\title{
Animal Spirits Through Creative Destruction
}

\author{
Patrick Francois \\ CentER and Dept. of Economics \\ Tilburg University \\ P.O. Box 90153 \\ 5000LE Tilburg \\ The Netherlands \\ p.francois@kub.nl
}

\author{
Huw Lloyd-Ellis \\ Department of Economics \\ Queen's University \\ Kingston, Ontario \\ Canada K7L 3N6 \\ (613) 5332276 \\ lloydell@qed.econ.queensu.ca
}

May 2002

\begin{abstract}
We show how a Schumpeterian process of creative destruction can induce rational, herdbehavior by entrepreneurs across diverse sectors of the economy that may look like it is fuelled by "animal spirits". Consequently, a multi-sector economy, in which sector-specific, productivity improvements are made by independent, profit-seeking entrepreneurs, can exhibit regular booms, slowdowns and downturns as an inherent part of the long-run growth process. The cyclical equilibrium that we study has a higher average growth rate but lower welfare than the corresponding acyclical one. We find that across cycling economies, a negative relationship emerges between volatility and growth, and that the cycles generated by our model exhibit several features of actual business cycles.
\end{abstract}

Key Words: Entrepreneurship, innovation, endogenous business cycles, endogenous growth JEL: E0, E3, O3, O4

We are grateful to Daron Acemoglu, Gadi Barlevy, Paul Beaudry, Francisco Gonzalez, Elhanan Helpman, Michael Krause, Joanne Roberts, Shouyong Shi, Gregor Smith, Gianluca Violante, Alwyn Young and two anonymous referees for helpful suggestions. We have also benefitted from the comments of seminar participants at Boulder, UIUC, Northwestern, Queen's, Toronto, UBC, Lausanne, the October 2000 CIAR meetings in Montreal, the 2001 NASEF meetings in Hydra and the 2001 CMSG meetings in Vancouver. Funding from Social Sciences and Humanities Research Council of Canada and the Canadian Institute for Advanced Research are gratefully acknowledged. The usual disclaimer applies. 
"The recurring periods of prosperity of the cyclical movement are the form progress takes in capitalistic society." (Joseph Schumpeter, 1927)

\section{Introduction}

Are business cycles simply random shocks around a deterministic trend, or are there more fundamental linkages between short-run fluctuations and long-run growth? Macroeconomists have tended to study the sources of fluctuations and the determinants of growth separately, but there are several reasons to question this standard dichotomy. First, post war cross-country evidence (e.g. Ramey and Ramey, 1995) suggests a significant negative partial correlation between volatility and growth, after controlling for standard growth correlates. This correlation is economically significant even amongst OECD countries. Second, while it is clear that some portion of aggregate volatility is the result of exogenous disturbances, the recurring asymmetry between the responses of the economy during upturns and downturns, is suggestive of an endogenously determined component (see also Freeman, Hong and Peled, 1999). Third, there is increasing evidence that the strength of cyclical upturns is related to the depth of preceding downturns (see Pesaran and Potter 1997 and Altissimo and Violante 2001). Finally, even for fluctuations that are typically associated with obvious aggregate shocks, the causal links are not clear. ${ }^{1}$

The view that growth and cycles are intimately linked is often associated with Schumpeter (1927). He argued that growth occurs through a process of "creative destruction" — competition amongst entrepreneurs in the search for new ideas that will render their rivals' ideas obsolete. This idea is central to modern theories of endogenous long run growth starting with Aghion and Howitt (1992), Grossman and Helpman (1991) and Sergestrom, Anant and Dinopolous (1990). However, Schumpeter also argued that this process of entrepreneurial innovation is responsible for the regular short-run fluctuations in economic activity, which he termed the "normal" business cycle. ${ }^{2}$ The key to explaining such business cycles, he argued, was to understand why entrepreneurial activity would be clustered over time. ${ }^{3}$

\footnotetext{
${ }^{1}$ For example, Zarnowitz (1998) argues that the US downturn in the early 1970s predates the 1974 oil price hike, suggesting that this shock simply made an underlying cyclical movement worse.

${ }^{2}$ The "normal" business cycle should be distinguished from the quarter-to-quarter fluctuations emphasized by the RBC literature. Rather it is more closely related to the NBER definition of a business cycle.

${ }^{3}$ Aghion and Howitt (1992) develop an identical engine of growth to Grossman and Helpman (1991) but differ in focusing on a model with a single innovating sector. Lumpy growth in Aghion and Howitt is possible, since there is no reason that single sectors should experience smooth growth. However, except by coincidence, this cannot
} 
One source of clustering was suggested by Schumpeter himself: “... as soon as any step in a new direction has been successfully made it, at once and thereby, becomes easy to follow... the first success draws other people in its wake and finally crowds of them, which is what the boom consists of." (Schumpeter, 1927). He further argued that there would be a downturn prior to the boom as resources are allocated to learning and imitation. Recently, several authors have formalized these "Schumpeterian cycles" in an attempt to understand their linkages to long-run growth. ${ }^{4}$ However, these theories rely on the arrival of major technological breakthroughs that influence all sectors - a General Purpose Technology (GPT). While the GPT story may be consistent with "long waves", most studies find little evidence to support the notion that such economy-wide advances can explain high frequency business cycles (see for example Jovanovic and Lach 1997, Andolfatto and MacDonald, 1998).

An alternative theory of why activity in diverse sectors of the economy may be clustered is developed by Shleifer (1986). He shows that when imitation limits the longevity of monopoly profits, a strategic complementarity arises that could lead entrepreneurs to implement innovations at the same time, even if the innovations themselves arrive uniformly through time. The clustering of implementation results in a boom in labor demand, which in turn generates the high demand for output necessary to support the boom. The temporary nature of the associated monopoly profits induces entrepreneurs to delay implementation until demand is maximized, so that a selfreinforcing cycle arises. Shleifer interprets his theory as a formalization of Keynes' (1936) notion of "animal spirits". 5

There are, however, several important limitations to Shleifer's theory of implementation cycles. Firstly, since innovations arrive exogenously, long-run growth is exogenous, so the theory has no implications for the impact of cycles on growth. Secondly, because of the multiplicity of equilibria that arise in his model, it is not possible to obtain precise predictions even for the effect of growth on cycles. Thirdly, the temporary nature of profits relies on the assumption of drastic, but costless imitation. It is not clear how robust the results would be to a less abrupt erosion of profits. Finally, Shleifer's theory depends critically on the impossibility of storage. If they could, innovators would explain the diffused productivity improvements observed over the business cycle. See Phillips and Wrase (1999) for further discussion.

${ }^{4}$ See, for example, Jovanovic and Rob (1990), Cheng and Dinopoulos (1992), Helpman and Trajtenberg (1998) and $\mathrm{Li}$ (2000). The literature on Schumpeterian cycles is discussed by Aghion and Howitt (1998), who note that GPTs are suited to generating Schumpeterian long waves.

${ }^{5}$ The expressions "animal spirits" is often associated with stochastic changes in the expectations of investors that turn out to be self-fulfilling. In the cyclical equilibrium that we study, however, the behavior of entrepreneurs may have the appearance of being fuelled by animal spirits, but in fact expectations are deterministic. 
choose to produce when costs are low (i.e. before the boom), store the output and then sell it when demand is high (i.e. in the boom). Such a pattern of production would undermine the existence of cycles. ${ }^{6}$

In this article, we draw on the insights of Schumpeter (creative destruction) and Shleifer (animal spirits), to develop a simple theory of endogenous, cyclical growth. We show how a multisector economy, in which sector-specific, productivity improvements are made by independent, profit-seeking entrepreneurs, can exhibit regular booms, slowdowns and downturns in economic activity as an inherent part of the long-run growth process. We establish the existence of a unique cyclical growth path along which the growth rate and the length and amplitude of cycles are endogenously determined. Our theory does not rely on the arrival of GPTs nor on drastic imitation, and allows for the possibility of storage. Specifically, we show that the process of creative destruction itself can induce endogenous clustering of implementation and innovation.

Creative destruction implies that the dissemination of knowledge caused by implementation eventually leads to improvements that limit a successful entrepreneur's time of incumbency. Anticipating this, entrants will optimally time implementation to ensure that their profits arrive at a time of non-depressed aggregate activity and that they maximize the length of their incumbency. It is these effects which lead to clustering in entrepreneurial implementation and, hence, to an aggregate level boom. If an entrepreneur implements before the boom, he reveals the information underlying his productivity improvement to potential rivals who may use this information in designing their own productivity improvements. By delaying implementation until the boom he delays reaping the rewards but maximizes his expected reign of incumbency. During the delay, entrepreneurs rely on maintaining secrecy regarding the nature of the innovations that they hold. ${ }^{7}$

Our cycle not only features clustering of implementation, but also endogenous clustering of innovation. It is this feature which generates the endogenous interactions between long-run growth and short-run fluctuations. After the boom, wage costs are so high that it is initially not profitable to undertake new entrepreneurial activities. As the next boom approaches, however, the present value of new innovations grows until at some point it becomes profitable to allocate entrepreneurial effort to innovation. As labor effort is withdrawn from production, per capita output

\footnotetext{
${ }^{6}$ Since questions of the timing of production and implementation clearly play an important role in producers' minds, we believe the clustering of innovations underlying the theory should at least be robust to the possibility of storage. For many goods, there is no reason to limit production to occuring only at the time of sale.

${ }^{7}$ As Cohen, Nelson and Walsh (2000) document, firms do indeed view secrecy as the best form of protection patenting is a less desired means of protecting knowledge.
} 
(and measured productivity) gradually decline. Eventually it becomes profitable to implement the stock of innovations that have accumulated during the downturn, and the cycle begins again.

We adopt a broad interpretation of innovation to include any improvement that is the outcome of purposive design in search of profit. Entrepreneurs are the source of refinements to process, organization and product improvements that increase productivity within narrowly defined sectors. The knowledge created by such entrepreneurial activity is both tacit and sector-specific. Unlike R\&D, or scientific knowledge, the improvements created may not be formally expressible (as in a blueprint or design) and need not lend themselves to protection by patent. It is our view that such mundane entrepreneurial decisions are the major source of high frequency productivity improvements, not the patentable R\&D improvements of a laboratory, which are often the focus in the growth literature. ${ }^{8}$ In modern production activities much of the entrepreneurial function has been allocated to managers and other skilled workers. It may therefore be more useful to think of innovation as requiring a reallocation of labor effort within firms. This interpretation is thus not unlike that of Hall (2000) who emphasizes the role of "reorganization" in a recession. ${ }^{9}$

Although our model is rather stylized, it has clear predictions for the interactions of long run growth and short run fluctuations. Firstly, the cycle in our model shows a positive feedback from both the duration and depth of downturns to the magnitude of succeeding upturns. This feature is consistent with the evidence of Beaudry and Koop (1993), Pesaran and Potter (1997) and Altissimo and Violante (2001). Secondly, the cycles generated by our model exhibit asymmetries in upturns and downturns that have some features in common with the evidence of Emery and Koenig (1992), Sichel (1993) and Balke and Wynne (1995). In particular, business cycles typically exhibit rapid growth in output at the beginning of the boom, a gradual slowdown and then a decline which occurs at a fairly constant rate. Thirdly, consistent with the evidence of Ramey and Ramey (1995), variation in the productivity of entrepreneurship induces a negative relationship between long run growth and output volatility.

Recently several authors have developed related, non-GPT models of endogenous growth and cycles. Francois and Shi (1999) modify the Grossman and Helpman (1991) growth model by allowing exogenous, drastic imitation (as in Shleifer 1986), by introducing a technological

\footnotetext{
${ }^{8}$ This view was shared by Schumpeter (1950, p.132): “...The function of entrepreneurs is to reform or revolutionize the pattern of production by exploiting an invention or, more generally, an untried technological possibility ... This function does not essentially consist in either inventing anything or otherwise creating the conditions which the enterprise exploits. It consists in getting things done".

${ }^{9}$ We discuss these alternative interpretations, and their empirical counterparts in Section 6.
} 
innovation process requiring accumulated inputs through time, and by treating the interest rate as exogenous. That model also inherits Shleifer's (1986) non-robustness to storage. In Matsuyama (1999) the clustering of innovations also results from the short-term nature of monopoly rents, though through a different channel. In his framework growth arises due to increasing product variety. Thus the upsurge in growth there arises through drastic innovations that represent wholly new (though partially substitutable) products, and is driven by a few leading sectors. This again lends itself more easily to a long cycle interpretation rather than the decentralized growth that we observe in the high volatility cycle. Freeman, Hong and Peled (1999) develop a model of cycles featuring a "time to build" component in innovation. As they emphasize, this technology describes "big" research or infrastructural projects, once again suggesting a long wave application of the cycle. However, the resulting dynamics of the economy are, at least superficially similar to those reported here.

The present paper proceeds as follows. Section 2 presents the economy's fundamentals and defines a general equilibrium, and, in Section 3, we show that one equilibrium of the model is an acyclical growth path that is qualitatively identical to that studied by Grossman and Helpman (1991). Section 4 presents the main results of the paper. We posit a cycle and derive the equilibrium behavior of households, firms and entrepreneurs that would be consistent with such a cycle. We then derive the sufficient conditions required for a unique cyclical equilibrium to exist, and show that the cyclical equilibrium is stable. Section 5 examines the implications of our equilibrium growth process for the endogenous relationship between long-run growth and shortrun volatility. We also compare the long run growth and welfare in the acyclical and cyclical equilibria. Section 6 considers the implications of our model for some aggregates over the cycle and compares these to available evidence. The final section concludes. Technical details of proofs and derivations are relegated to the appendix.

\section{The Model}

\subsection{Assumptions}

Time is continuous and indexed by $t$. We consider a closed economy with no government sector. Households have isoelastic preferences

$$
U(t)=\int_{t}^{\infty} e^{-\rho(s-t)} \frac{c(s)^{1-\sigma}}{1-\sigma} d s
$$


where $\rho$ denotes the rate of time preference and we assume that $\sigma \in(0,1)$. Each household maximizes (1) subject to the intertemporal budget constraint

$$
\int_{t}^{\infty} e^{-[R(\tau)-R(t)]} c(\tau) d \tau \leq B(t)+\int_{t}^{\infty} e^{-[R(\tau)-R(t)]} w(\tau) d \tau
$$

where $w(t)$ denotes wage income, $B(t)$ denotes the household's stock of assets at time $t$ and $R(t)$ denotes the discount factor from time zero to $t$.

Final output is produced by competitive firms according to a Cobb-Douglas production function utilizing intermediates, $k$, indexed by $i$, over the unit interval:

$$
y(t)=\exp \left(\int_{0}^{1} \ln k_{i}(t) d i\right)
$$

Final output is storable (at an arbitrarily small cost), but cannot be converted back into an input for use in production. We let $p_{i}$ denote the price of intermediate $i$.

Output of intermediate $i$ depends upon the state of technology in sector $i, A_{i}(t)$, and the labor resources devoted to production, $l_{i}$, in a linear manner:

$$
k_{i}^{s}(t)=A_{i}(t) l_{i}(t)
$$

Labor receives the equilibrium wage $w(t)$. There is no imitation, so the dominant entrepreneur in each sector undertakes all production and earns monopoly profits by limit pricing until displaced by a higher productivity rival. We assume that intermediates are completely used up in production, but can be produced and stored for use at a later date. Incumbent intermediate producers must therefore decide whether to sell now, or store and sell later.

Competitive entrepreneurs in each sector attempt to find ongoing marginal improvements in productivity by diverting labor effort away from production and towards innovation. ${ }^{10}$ They finance their activities by selling equity shares to households. The probability of an entrepreneurial success in instant $t$ is $\delta x_{i}(t)$, where $\delta$ is a parameter, and $x_{i}$ is the labor effort allocated to entrepreneurship in sector $i$. At any point in time, entrepreneurs decide whether or not to allocate labor effort to innovation, and if they do so, how much. The aggregate labor effort allocated to entrepreneurship is given by $X(t)=\int_{0}^{1} x_{i}(t) d t$.

New innovations dominate old ones by a factor $e^{\gamma}$. Entrepreneurs with innovations must choose whether or not to implement their innovation immediately or delay implementation until a

\footnotetext{
${ }^{10}$ This process can equivalently be thought of as a search for product improvements, process improvements, organizational advances or anything else in the form of new knowledge which creates a productive advance over the existing state of the art.
} 
later date. Once they implement, the knowledge associated with the innovation becomes publicly available, and can be built upon by rival entrepreneurs. However, prior to implementation, the knowledge is privately held by the entrepreneur. We let the indicator function $Z_{i}(t)$ take on the value 1 if there exists a successful innovation in sector $i$ which has not yet been implemented, and 0 otherwise. The set of periods in which innovations are implemented in sector $i$ is denoted by $\Omega_{i}$. We let $V_{i}^{I}(t)$ denote the expected present value of profits from implementing an innovation at time $t$, and $V_{i}^{D}(t)$ denote that of delaying implementation from time $t$ until the most profitable time in future.

Finally, we assume the existence of arbitrageurs who instantaneously trade assets to erode any profit opportunities. There are three potential assets in our economy: claims to the profits of intermediate firms, stored intermediate output and stored final output. As we shall see, in all of the equilibria discussed below, only claims to the profits of intermediate firms will be traded - intermediate and final output are never stored. However, the potential for stored output to be traded imposes restrictions on the possible equilibria that can emerge.

In summary, our model is formally identical to that developed by Grossman and Helpman (1991), but with an elasticity of intertemporal substitution, $1 / \sigma$, that exceeds unity. However, we have expanded the set of possible strategies by divorcing the realization of innovations from the decision to implement them (as in Shleifer, 1986) and by allowing intermediate output to be potentially storable.

\subsection{Definition of Equilibrium}

Given an initial stock of implemented innovations represented by a cross-sectoral distribution of productivities $\left\{A_{i}(0)\right\}_{i=0}^{1}$ and an initial distribution of unimplemented innovations, $\left\{Z_{i}(0)\right\}_{i=0}^{1}$, an equilibrium for this economy satisfies the following conditions:

- Households allocate consumption over time to maximize (1) subject (2). The first-order conditions of the household's optimization require that

$$
c(t)^{\sigma}=c(s)^{\sigma} e^{R(t)-R(s)-\rho(t-s)} \quad \forall t, s,
$$

and that the transversality condition holds

$$
\lim _{s \rightarrow \infty} e^{-R(s)} B(s)=0
$$


- Final goods producers choose intermediates to maximize profits. The derived demand for intermediate $i$ is then

$$
k_{i}^{d}(t)=\frac{y(t)}{p_{i}(t)}
$$

- Intermediate producers set prices. It follows that the price of intermediate $i$ is given by

$$
p_{i}(t)=\frac{w(t)}{e^{-\gamma} A_{i}(t)}
$$

and the instantaneous profit earned is

$$
\pi_{i}(t)=\left(1-e^{-\gamma}\right) y(t)
$$

Note crucially that firm profits are proportional to aggregate demand.

- Labor market clearing:

$$
\int_{0}^{1} l_{i}(t) d i+X(t)=1
$$

Labor market equilibrium also implies

$$
w(t)(1-X(t))=e^{-\gamma} y(t)
$$

- Free entry into arbitrage. For all assets that are held in strictly positive amounts by households, the rate of return between time $t$ and time $s$ must equal $\frac{R(s)-R(t)}{s-t}$.

- There is free entry into innovation. Entrepreneurs select the sector in which they innovate so as to maximize the expected present value of the innovation. Also

$$
\delta \max \left[V_{i}^{D}(t), V_{i}^{I}(t)\right] \leq w(t), \quad x_{i}(t) \geq 0 \quad \text { with at least one equality }
$$

- In periods where there is implementation, entrepreneurs with innovations must prefer to implement rather that delay until a later date

$$
V_{i}^{I}(t) \geq V_{i}^{D}(t) \quad \forall t \in \Omega_{i}
$$

- In periods where there is no implementation, either there must be no innovations available to implement, or entrepreneurs with innovations must prefer to delay rather than implement:

$$
\begin{aligned}
\text { Either } Z_{i}(t) & =0, \\
\text { or if } Z_{i}(t) & =1, V_{i}^{I}(t) \leq V_{i}^{D}(t) \quad \forall t \notin \Omega_{i} .
\end{aligned}
$$

In what follows we characterize two types of equilibria that satisfy these conditions. The first mirrors the familiar acyclical growth path analyzed by Grossman and Helpman (1991). However, the second is a growth path featuring regular downturns and upsurges in economic activity. 


\section{The Acyclical Equilibrium}

Along an acyclical growth path, the rate of innovation is constant and output grows at a constant rate. The key feature of this equilibrium is that innovation occurs every period and implementation occurs immediately, so that $Z_{i}(t)=0 \forall i, t$. Although this growth path is well understood, it is useful to briefly outline the equilibrium and, in particular, to see why implementation of innovations is never delayed.

In the acyclical equilibrium, consumption is a continuous function of time and its growth rate can be described by the familiar differential equation

$$
\frac{\dot{c}(t)}{c(t)}=\frac{r(t)-\rho}{\sigma}
$$

where $r(t)=\dot{R}$ denotes the instantaneous interest rate. Since all innovations are implemented immediately, the aggregate rate of productivity growth is

$$
g(t)=\delta \gamma X(t)
$$

No-arbitrage implies that

$$
r(t)+\delta X(t)=\frac{\pi(t)}{V(t)}+\frac{\dot{V}(t)}{V(t)}
$$

Since, innovation occurs in every period, free entry into entrepreneurship implies that

$$
\delta V(t)=w(t)
$$

Putting these conditions together yields:

Proposition 1 : If

$$
\left(1-e^{-\gamma}\right) \gamma(1-\sigma)<\frac{\rho}{\delta}<e^{\gamma}-1
$$

then there exists an acyclical equilibrium with a constant growth rate given by

$$
g^{a}=\frac{\left[\delta\left(1-e^{-\gamma}\right)-\rho e^{-\gamma}\right] \gamma}{1-\gamma(1-\sigma) e^{-\gamma}}
$$

Along this equilibrium growth path the first inequality in (19) implies that $r(t)>g^{a}(t)$ at every moment. ${ }^{11}$ Along a balanced growth path, this condition must hold for the transversality condition to be satisfied and hence for utility to be bounded. However, this condition also

\footnotetext{
${ }^{11}$ The second condition in Proposition 1 ensures that entrepreneurs are sufficiently profitable to warrant investment, when $\sigma<1$. Otherwise growth would be zero.
} 


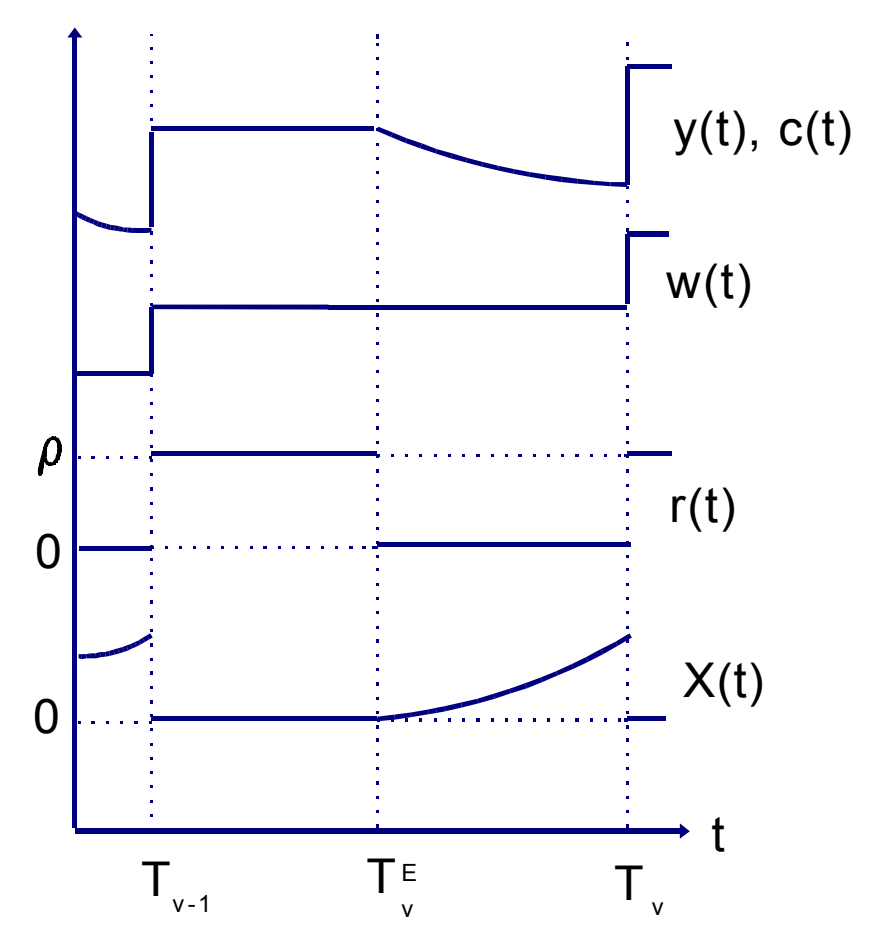

Figure 1: The Cyclical Growth Path

ensures both that no output is stored, and that the implementation of any innovation is never delayed. The return on storage is the growth in the price of the intermediate good in noninnovating sectors, which in turn equals $g^{a}(t)$. Thus, since $r(t)>g^{a}(t)$, it never pays to store the intermediate. ${ }^{12}$ That delay is never optimal in this equilibrium can be seen by considering the extreme case where obsolescence is certain after implementation. In this case the gain from delay is the growth in profits equal to $g^{a}(t)$. However, since this gain is discounted at the rate $r(t)$, immediate implementation is always optimal. If obsolescence is not certain, the relative gain from immediate implementation is even greater.

\section{The Cyclical Equilibrium}

In this section we posit a cyclical growth path along which innovations are implemented in clusters rather than in a smooth fashion. We derive the optimal behavior of agents in such a cyclical equilibrium and the evolution of the key variables under market clearing. We derive sufficient

\footnotetext{
${ }^{12}$ Obviously, since $r>0$, final output is never stored either.
} 
conditions for the existence of such a cyclical equilibrium and show that market clearing implies a unique positive cycle length and long run growth rate.

Suppose that the implementation of entrepreneurial innovations occurs at discrete intervals. An implementation period is denoted by $T_{\nu}$ where $v \in\{1,2, \ldots, \infty\}$, and we adopt the convention that the $v$ th cycle starts in period $T_{v-1}$ and ends in period $T_{\nu}$. The evolution of final output during a typical cycle between implementation periods is depicted in Figure 1. A boom occurs when accumulated innovations are implemented at $T_{v-1}$. After that there is an interval during which no entrepreneurial effort is devoted to improvement of existing technologies and consequently where all resources are used in production. During this interval, no new innovations are implemented so that growth slows to zero. At some time $T_{v}^{E}$ innovation commences again, but successful entrepreneurs withhold implementation until time $T_{v}$. Entrepreneurial activity occurs throughout the interval $\left[T_{v}^{E}, T_{v}\right]$ and causes a decline in the economy's production, as resources are diverted away from production towards the search for improvements. At $T_{v}$ all successful entrepreneurs implement, and the $(v+1)$ th cycle starts with a boom.

Over intervals during which the discount factor does not jump, consumption is allocated as described by (15). However, as we will demonstrate here, along the cyclical growth path, the discount rate jumps at the boom, so that consumption exhibits a discontinuity during implementation periods. We therefore characterize the optimal evolution of consumption from the beginning of one cycle to the beginning of the next by the difference equation

$$
\sigma \ln \frac{c_{0}\left(T_{v}\right)}{c_{0}\left(T_{v-1}\right)}=R\left(T_{v}\right)-R\left(T_{v-1}\right)-\rho\left(T_{v}-T_{v-1}\right) .
$$

where the 0 subscript is used to denote values of variables the instant after the implementation boom. Note that a sufficient condition for the boundedness of the consumer's optimization problem is that $\ln \frac{c_{0}\left(T_{v}\right)}{c_{0}\left(T_{v-1}\right)}<R\left(T_{v}\right)-R\left(T_{v-1}\right)$ for all $v$, or that

$$
\frac{1}{T_{v}-T_{v-1}} \ln \frac{c_{0}\left(T_{v}\right)}{c_{0}\left(T_{v-1}\right)}<\frac{\rho}{1-\sigma} \quad \forall v
$$

In our analysis below, it is convenient to define the discount factor that will be used to discount from some time $t$ during the cycle to the beginning of the next cycle. This discount factor is given by

$$
\beta(t)=R\left(T_{v}\right)-R(t)=R\left(T_{v}\right)-R\left(T_{v-1}\right)-\int_{T_{v-1}}^{t} r(s) d s
$$




\subsection{Entrepreneurship}

Let $P_{i}(s)$ denote the probability that, since time $T_{v}$, no entrepreneurial success has been made in sector $i$ by time $s$. It follows that the probability of there being no innovation by time $T_{v+1}$ conditional on there having been none by time $t$, is given by $P_{i}\left(T_{v+1}\right) / P_{i}(t)$. Hence, the value of an incumbent firm in a sector where no innovation has occurred by time $t$ during the $v$ th cycle can be expressed as

$$
V_{i}^{I}(t)=\int_{t}^{T_{v+1}} e^{-\int_{t}^{\tau} r(s) d s} \pi_{i}(\tau) d \tau+\frac{P_{i}\left(T_{v+1}\right)}{P_{i}(t)} e^{-\beta(t)} V_{0, i}^{I}\left(T_{v+1}\right)
$$

The first term here represents the discounted profit stream that accrues to the entrepreneur with certainty during the current cycle, and the second term is the expected discounted value of being an incumbent thereafter.

In the acyclical equilibrium, the role of secrecy is not relevant because innovators would always prefer to implement even if it were possible that, by delaying, they could protect their knowledge. Since simultaneous innovation can only occur with a second order probability in that equilibrium, it is assumed away. In the cyclical equilibrium considered here, secrecy (i.e. protecting the knowledge embodied in a new innovation by delaying implementation) can be a valuable option. ${ }^{13}$ Innovations are withheld until a common implementation time, so that simultaneous implementation is a possibility. However, as the following Lemma demonstrates, such duplications do not arise in the cyclical equilibrium:

Lemma 1 In a cyclical equilibrium, successful entrepreneurs can credibly signal a success immediately and all research in their sector will stop until the next round of implementation.

If an entrepreneur's announcement is credible, other entrepreneurs will exert their efforts in sectors where they have a better chance of becoming the dominant entrepreneur. One might imagine that unsuccessful entrepreneurs would have an incentive to mimic successful ones by falsely announcing success to deter others from entering the sector. But there is no advantage to this strategy relative to the alternative of allocating effort to the sector until, with some probability, another entrepreneur is successful, and then switching to another sector. ${ }^{14}$

\footnotetext{
${ }^{13}$ As Cohen, Nelson and Walsh (2000) document, delaying implementation to protect knowledge is a widely followed practice in reality.

${ }^{14}$ With an arbitrarily small signalling cost, the equilibrium would involve strictly dominant strategies. This equilibrium relies on the memoryless nature of the Poisson process governing innovation. However, with memory a similar shutting down of innovation after a success would arise if innovative effort is directly observable so that success can be inferred. In this case, however, it must not be possible for outsiders to observe the direction of the innovative effort, otherwise incumbents might allocate effort in their own sectors to deter entry.
} 
In the cyclical equilibrium, entrepreneurs' conjectures ensure no more entrepreneurship in a sector once a signal of success has been received, until after the next implementation. The expected value of an entrepreneurial success occurring at some time $t \in\left(T_{v}^{E}, T_{v}\right)$ but whose implementation is delayed until time $T_{v}$ is thus:

$$
V_{i}^{D}(t)=e^{-\beta(t)} V_{0, i}^{I}\left(T_{v}\right)
$$

Since no implementation occurs during the cycle, the entrepreneur is assured of incumbency until at least $T_{v+1}$. Incumbency beyond that time depends on the probability that there has not been another successful innovation in that sector up until then. ${ }^{15}$ The symmetry of sectors implies that innovative effort is allocated evenly over all sectors that have not yet experienced an innovation within the cycle. Thus the probability of not being displaced at the next implementation is

$$
P_{i}\left(T_{v}\right)=\exp \left(-\int_{T_{v}^{E}}^{T_{v}} \delta \tilde{x}_{i}(\tau) d \tau\right)
$$

where $\tilde{x}_{i}(\tau)$ denotes the quantity of labor that would be allocated to entrepreneurship if no innovation had been discovered prior to time $\tau$ in sector $i$. The amount of entrepreneurship varies over the cycle, but at the beginning of each cycle all industries are symmetric with respect to this probability: $P_{i}\left(T_{v}\right)=P\left(T_{v}\right) \forall i$.

\subsection{Within-cycle dynamics}

Within a cycle, $t \in\left[T_{v-1}, T_{v}\right]$, the state of technology in use is unchanging. A critical variable is the amount of labor devoted to entrepreneurship, the opportunity cost of which is production. In order to determine this, we first characterize wages paid to labor in production.

Lemma 2 The wage for $t \in\left[T_{v-1}, T_{v}\right]$ is pinned down by the level of technology

$$
w(t)=e^{-\gamma} \exp \left(\int_{0}^{1} \ln A_{i}\left(T_{v-1}\right) d i\right)=w_{v} .
$$

The wage is completely pinned down by the technology given competition between the producing firms in attempting to hire labor. This competition does not drive the wage up to labor's

\footnotetext{
${ }^{15} \mathrm{~A}$ signal of further entrepreneurial success submitted by an incumbent is not credible in equilibrium. This is for the standard reason that innovation in other sectors is always more profitable than innovation in one's own, so that an incumbent's success signals do not dissuade innovation.
} 
marginal product because firms earn monopolistic rents. However, it does ensure that labor benefits proportionately from productivity advancements. We denote the improvement in aggregate productivity during implementation period $T_{v}$ (and, hence, the growth in the wage) by $e^{\Gamma_{v}}$, where

$$
\Gamma_{v}=\int_{0}^{1}\left[\ln A_{i}\left(T_{v}\right)-\ln A_{i}\left(T_{v-1}\right)\right] d i
$$

Since wages are determined by the level of technology in use, and since this does not change within the cycle, wages are constant within the cycle.

Following an implementation boom, the economy passes through two distinct phases:

\section{The Slowdown:}

As a result of the boom, wages rise rapidly. Since the next implementation boom is some time away, the present value of engaging in innovation falls below the wage, $\delta V^{D}(t)<w(t)$. During this phase, no labor is allocated to entrepreneurship and no new innovations come on line. Since technology is unchanging, final output must be constant

$$
g(t)=\frac{\dot{w}(t)}{w(t)}=0
$$

With zero growth, the demand side of the economy dictates that the interest rate just equal the discount rate,

$$
r(t)=\sigma g(t)+\rho=\rho .
$$

Since the economy is closed, and there is no incentive to store either intermediate or final output when $r(t) \geq 0$, it must be the case that:

$$
c(t)=y(t)
$$

During the slowdown, the expected value of entrepreneurship, $\delta V^{D}(t)$, is necessarily growing at the rate of interest, $r(t)=\rho$, but continues to be dominated by the wage in production. Since the wage is constant during the cycle, $\delta V^{D}(t)$, must eventually equal $w(t)$. At this point, the entrepreneurship commences. The following Lemma demonstrates that it does so smoothly:

Lemma 3 At time $T_{v}^{E}$, when entrepreneurship first commences in a cycle, $w_{v}=\delta V^{D}(t)$ and $X\left(T_{v}^{E}\right)=0$.

\section{The Downturn:}

For positive entrepreneurship to occur under free entry, it must be that $w_{v}=\delta V^{D}(t)$. Since the wage is constant throughout the cycle, $\delta V^{D}(t)$ must also be constant during this phase. Since 
the time until implementation for a successful entrepreneur is falling and there is no stream of profits because implementation is delayed, the instantaneous interest rate must be zero.

$$
r(t)=\frac{\dot{V}^{D}(t)}{V^{D}(t)}=\frac{\dot{w}(t)}{w(t)}=0 .
$$

With a positive discount rate, $\rho>0$, a zero interest rate implies that consumption must be declining. Since the economy is closed, it follows once again that, because there is no incentive to store output, (31) holds. ${ }^{16}$ Hence, per capita output must also decline:

$$
g(t)=\frac{r(t)-\rho}{\sigma}=-\frac{\rho}{\sigma}
$$

This occurs during the downturn because labor flows out of production and into entrepreneurship (knowledge capital is being built). Using (11), (33) and the fact that $X\left(T_{v}^{E}\right)=0$, yields the following expression for aggregate entrepreneurship at time $t$ :

$$
X(t)=1-e^{-\frac{\rho}{\sigma}\left[t-T_{v}^{E}\right]} .
$$

The proportion of sectors that have not yet experienced an entrepreneurial success by time $t \in\left(T_{v}^{E}, T_{v}\right)$ is given by

$$
P(t)=\exp \left(-\int_{T_{v}^{E}}^{t} \delta x(\tau) d \tau\right) .
$$

Recalling that labor is only devoted to entrepreneurship in sectors which have not innovated since the start of the cycle, the labor allocated to entrepreneurship in each sector is then

$$
x(t)=\frac{X(t)}{P(t)} .
$$

Differentiating (35), and substituting in (36), we thus obtain the aggregate rate of entrepreneurial success,

$$
\dot{P}(t)=-\delta x(t) P(t)=-\delta X(t)
$$

Observe that although the rate of decline in the proportion of sectors that have not yet innovated, $P(t)$, is proportional to the amount of entrepreneurship in each sector, the level reductions in $P$ are proportional to the aggregate amount of entrepreneurship. This reflects the fact that as new innovations arise, aggregate innovative effort is allocated across fewer and fewer sectors. We characterize an equilibrium in which the cycle is never long enough that all sectors innovate, $P\left(T_{v}\right)<1$. The parameter restrictions that ensure this is the case are discussed in Section 4.5.

\footnotetext{
${ }^{16}$ Although $r=0$, strict preference for zero storage results from arbitrarily small storage costs.
} 
The dynamic movement of variables implied by our hypothesized cycle is sketched in Figure 1. The resulting allocation of labor to entrepreneurship (34) determines the size of the output boom at the end of the cycle. Denote the interval over which there is positive entrepreneurship by

$$
\Delta_{v}^{E}=T_{v}-T_{v}^{E}
$$

Then we have:

Proposition 2 In an equilibrium where there is positive entrepreneurship only over the interval $\left(T_{v}^{E}, T_{v}\right]$, the growth in productivity during the succeeding boom is given by

$$
\Gamma_{v}=\delta \gamma \Delta_{v}^{E}-\delta \gamma\left(\frac{1-e^{-\frac{\rho}{\sigma} \Delta_{v}^{E}}}{\rho / \sigma}\right) .
$$

Equation (39) tells us how the size of the productivity boom depends positively on the amount of time the economy is in the entrepreneurship phase, $\Delta_{v}^{E}$. The amount of innovation in that phase is determined by the movements in the interest rate, so once the length of the entrepreneurship phase is known, the growth rate over the cycle is pinned down. The size of the boom is convex in $\Delta_{v}^{E}$, reflecting the fact that as the boom approaches, the labor allocated towards innovation is increasing. This also implies that the boom size is increasing in the depth of the downturn, since from (34) the longer the downturn the greater the allocation of innovative effort and hence the larger the decline in output.

\subsection{Market Clearing During the Boom}

For an entrepreneur who is holding an innovation, $V^{I}(t)$ is the value of implementing immediately. Just prior to the boom, when the probability of displacement is negligible, the value of implementing immediately must equal that of delaying until the boom:

$$
\delta V^{I}\left(T_{v}\right)=\delta V^{D}\left(T_{v}\right)=w_{v}
$$

During the boom, since entrepreneurs prefer to implement immediately, it must be the case that $V_{0}^{I}\left(T_{v}\right)>V_{0}^{D}\left(T_{v}\right)$. Thus the return to innovation at the boom is the value of immediate (rather than delayed) incumbency. It follows that free entry into entrepreneurship at the boom requires that

$$
\delta V_{0}^{I}\left(T_{v}\right) \leq w_{v+1}
$$


The opportunity cost to financing entrepreneurship is the rate of return on shares in incumbent firms in sectors where no innovation has occurred. Just prior to the boom, this is given by the capital gains in sectors where no innovations have occurred

$$
\beta\left(T_{v}\right)=\log \left(\frac{V_{0}^{I}\left(T_{v}\right)}{V^{I}\left(T_{v}\right)}\right) .
$$

Note that since the short-term interest rate is zero over this phase, $\beta(t)=\beta\left(T_{v}\right), \forall t \in\left(T_{v}^{E}, T_{v}\right)$. Combined with (40) and (41) it follows that asset market clearing at the boom requires

$$
\beta\left(T_{v}\right) \leq \log \left(\frac{w_{v+1}}{w_{v}}\right)=\Gamma_{v}
$$

Provided that $\beta(t)>0$, households will never choose to store final output from within a cycle to the beginning of the next because it is dominated by the long-run rate of return on claims to future profits. However, unlike final output, the return on stored intermediate output in sectors with no innovations, is strictly positive because of the increase in its price that occurs as a result of the boom. Even though there is a risk that the intermediate becomes obsolete at the boom, if the anticipated price increase is sufficiently large, households may choose to purchase claims to intermediate output rather than claims to firm profits. ${ }^{17}$

If innovative activities are to be financed at time $t$, households cannot be strictly better off buying claims to stored intermediate goods. There are two types of storage that could arise, but the return to each is the same. In sectors with unimplemented innovations, entrepreneurs who hold innovations have the option of implementing immediately but not actually selling until the boom. The best way to do this is to hire labor and produce an instant prior to the boom; producing any earlier will not be any cheaper and will yield a higher probability of displacement. Also, the best time to sell is an instant after the boom, since after the boom interest rates are positive and demand is flat. Since the revenue is the same, the difference between producing an instant before the boom and an instant after the boom, is that the former involves the current wage and the latter involves the higher future wage. Thus, the return on claims to stored intermediates is $\log w_{v+1} / w_{v}=\Gamma_{v}$. In sectors with no innovation, incumbent firms could sell such claims, use them to finance greater current production and then store the good to sell at the beginning of

\footnotetext{
${ }^{17}$ Since returns to innovation are identical across sectors, one may suppose that incumbents have an incentive to store intermediate production and threaten to use it to undercut any future innovator in their sector. If credible, such a threat would lead outside entrepreneurs to search for innovations in other sectors. However, such a threat is not credible. If faced with an innovator holding a productive advantage that will be implemented at time $T$, an incumbent would always have incentive to sell stockpiled intermediates before time $T$ since by doing so they would obtain a higher price than by delaying and selling it in competition with the new innovator.
} 
the next boom when the price is higher. In this case, since the cost of production is the same whether the good is stored or not, the rate of return on claims to stored intermediates in sector $i$ is $\log p_{i, v+1} / p_{i, v}=\Gamma_{v}$.

It follows that the long run rate of return on claims to firm profits an instant prior to the boom must satisfy

$$
\beta\left(T_{v}\right) \geq \Gamma_{v}
$$

Because there is a risk of obsolescence, this condition implies that at any time prior to the boom the expected rate of return on claims to stored intermediates is strictly less than $\beta(t)$.

Combining (43) and (44), and observing that $\beta\left(T_{v}\right)=\sigma \Gamma_{v}+\rho \Delta_{v}^{E}$, yields the following implication of market clearing during the boom for the long-run growth path:

Proposition 3 Long run asset market clearing requires that

$$
\Gamma_{v}=\frac{\rho \Delta_{v}^{E}}{1-\sigma}
$$

Since the short term interest rate during the downturn is zero, asset market clearing requires that the long term interest rate at the end of the downturn is equal to its value at the beginning. The value at the end must equal the size of the productivity boom in equilibrium; the value at the beginning reflects the size of the future boom and the time until it occurs. It follows that asset market-clearing yields a unique relationship between the length of the downturn and the size of the subsequent productivity boom.

Figure 2 depicts the two conditions (39) and (45) graphically. As shown by the solid lines, combining the two conditions yields a unique (non-zero) equilibrium pair $\left(\Gamma, \Delta^{E}\right)$ that is consistent with the within-cycle dynamics and the asset market clearing condition. Combining them implies that $\Delta^{E}$ must satisfy

$$
\left(1-\frac{\rho}{\delta \gamma(1-\sigma)}\right) \Delta^{E}=\frac{1-e^{-\frac{\rho}{\sigma} \Delta^{E}}}{\rho / \sigma}
$$

Note that although we did not impose any stationarity on the cycles, the equilibrium conditions imply stationarity of the size of the boom and the length of the downturn. For a unique positive value of $\Delta^{E}$ that satisfies this condition to exist it is sufficient that $\frac{\rho}{\delta \gamma(1-\sigma)}<1$. 


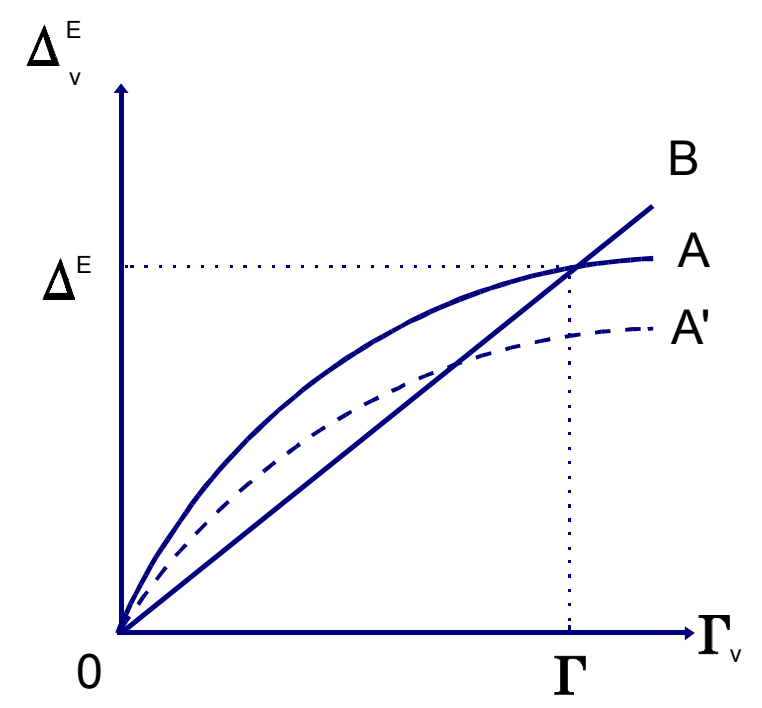

Figure 2: Equilibrium Recession length and Boom Size

\subsection{Optimal Entrepreneurial Behavior}

It has thus far been assumed that entrepreneurs are willing to follow the innovation and implementation sequence hypothesized in the cycle. The equilibrium conditions that we have considered so far effectively assume that entrepreneurs who plan to innovate will implement at $T_{v}$ and that they start innovation at $T_{v}^{E}$. However, the willingness of entrepreneurs to delay implementation until the boom and to just start engaging in innovative activities at exactly $T_{v}^{E}$ depends crucially on the expected value of monopoly rents resulting from innovation, relative to the current labor costs. This is a forward looking condition: given $\Gamma$ and $\Delta^{E}$, the present value of these rents depend crucially on the length of the subsequent cycle, $T_{v+1}-T_{v}$.

Since Lemma 3 implies that entrepreneurship starts smoothly at $T_{v}^{E}$, free entry into entrepreneurship, requires that

$$
\delta V^{D}\left(T_{v}^{E}\right)=\delta e^{-\beta\left(T_{v}^{E}\right)} V_{0}^{I}\left(T_{v}\right)=w_{v}
$$

Since the increase in the wage across cycles reflects only the improvement in productivity: $w_{v+1}=e^{\Gamma} w_{v}$, and since from the asset market clearing conditions, we know that $\beta\left(T_{v}^{E}\right)=\Gamma$, it immediately follows that the increase in the present value of monopoly profits from the beginning of one cycle to the next must, in equilibrium, reflect only the improvements in aggregate productivity:

$$
V_{0}^{I}\left(T_{v+1}\right)=e^{\Gamma} V_{0}^{I}\left(T_{v}\right) .
$$


Equation (48) implies that, given some initial implementation period, and stationary values of $\Gamma$ and $\Delta^{E}$, the next implementation period is determined. Notice, once again that this stationarity is not imposed, but is an implication of the equilibrium conditions. Letting $\Delta_{v}=T_{v}-T_{v-1}$, we therefore have the following result:

Proposition 4 Given the boom size, $\Gamma$, and the length of the entrepreneurial innovation phase, $\Delta^{E}$, there exists a unique cycle length, $\Delta$, such that entrepreneurs are just willing to commence innovation, $\Delta^{E}$ periods prior to the boom.

In the appendix we show that the implied cycle length is given by

$$
\Delta=\Delta^{E}+\frac{1}{\rho} \ln \left[1+\mu \Delta^{E}\right]
$$

where

$$
\mu=\left(\frac{\rho}{\delta \gamma(1-\sigma)}-\left(1-e^{-\gamma}\right)\right) /\left(\frac{1-e^{-\gamma}}{\rho}-\frac{e^{-\gamma}}{\delta}\right)>0
$$

In addition, the equilibrium conditions (12), (13) and (14) on entrepreneurial behavior also impose the following requirements on our hypothesized cycle:

- Successful entrepreneurs at time $t=T_{v}$, must prefer to implement immediately, rather than delay implementation until later in the cycle or the beginning of the next cycle:

$$
V_{0}^{I}\left(T_{v}\right)>V_{0}^{D}\left(T_{v}\right)
$$

- Entrepreneurs who successfully innovate during the downturn must prefer to wait until the beginning of the next cycle rather than implement earlier:

$$
V^{I}(t)<V^{D}(t) \quad \forall t \in\left(T_{v}^{E}, T_{v}\right)
$$

- No entrepreneur wants to innovate during the slowdown of the cycle. Since in this phase of the cycle $\delta V^{D}(t)<w(t)$, this condition requires that

$$
\delta V^{I}(t)<w(t) \quad \forall t \in\left(0, T_{v}^{E}\right)
$$

Figure 3 illustrates the evolution of the relevant value functions in the cyclical equilibrium, and the productivity adjusted wage $w_{v} / \delta$. At the beginning of the cycle $w_{v}=\delta V^{I}\left(T_{v}\right)>\delta V^{D}\left(T_{v}\right)$. Since the wage is constant, $\delta V^{D}(t)$ grows and $\delta V^{I}(t)$ declines during the first phase of the cycle, 


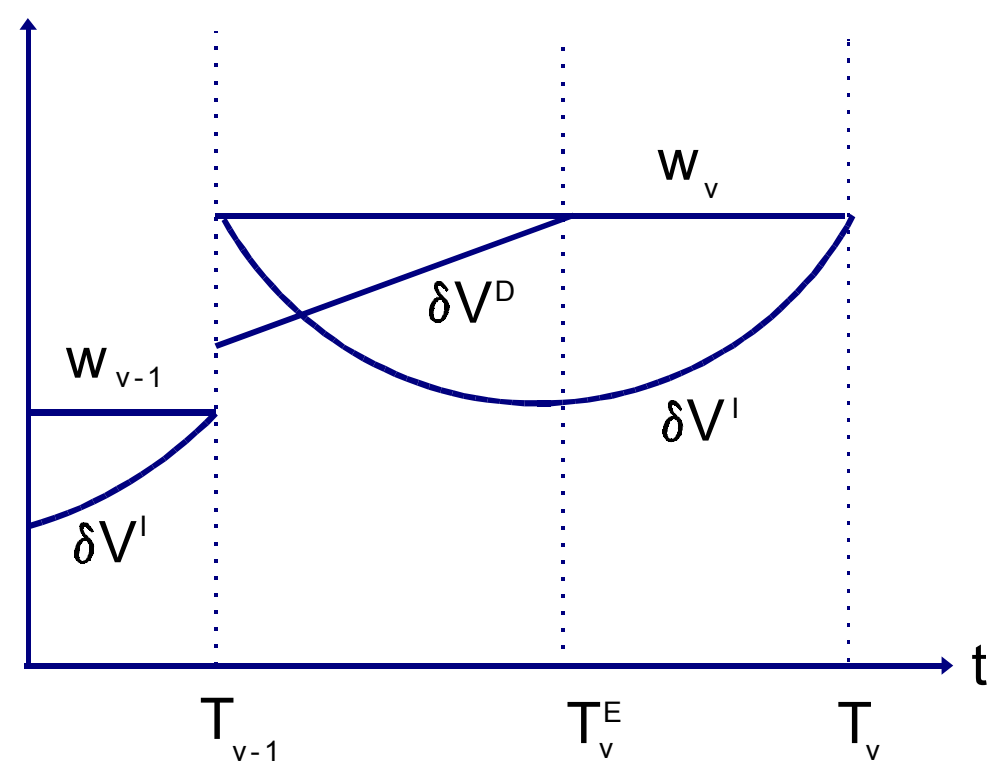

Figure 3: Evolution of Value Functions

this condition implies that $\delta V^{D}(t)$ and $\delta V^{I}(t)$ must intersect before $\delta V^{D}(t)$ reaches $w(t)$. It follows that when entrepreneurship starts, it is optimal to delay implementation, $V^{D}\left(T_{v}^{E}\right)>$ $V^{I}\left(T_{v}^{E}\right)$. Over time, during the entrepreneurship phase, the probability of not being displaced at the boom if you implement early declines so that $V^{I}(t)$ rises. Eventually, an instant prior to the boom, $V^{I}\left(T_{v+1}\right)=V^{D}\left(T_{v+1}\right)$, but until that point it continues to be optimal to delay. At the boom, the value of immediate implementation rises by more than the value of delay, so that all existing innovations are implemented. However, since the wage increases by at least as much as $V^{I}(t)$, entrepreneurship ceases and the cycle begins again.

\subsection{Existence}

In constructing the equilibrium above we have implicitly imposed the requirement that the downturn is not long enough that all sectors innovate:

$$
P(T)>0 \text {. }
$$

The following proposition demonstrates that there is a non-empty parameter space such that the triple $\left(\Delta^{E}, \Delta, \Gamma\right)>0$ solving (39), (45) and (49) also implies that conditions (E1), (E2), (E3) and (E4) are satisfied. 


\section{Proposition 5 If}

$$
\max \left[\left(1-e^{-\gamma}\right) \gamma(1-\sigma), \gamma(1-\sigma)-\sigma\right]<\frac{\rho}{\delta}<\gamma(1-\sigma)-\sigma\left(1-e^{-\left(\frac{1-\sigma}{\sigma}\right) \gamma}\right)
$$

then there exists a unique cyclical equilibrium growth path, $\left(\Delta^{E}, \Delta, \Gamma\right)$.

The left-hand inequality in (51) is sufficient for (E1) to hold. This is equivalent to the transversality condition that the long run interest rate exceeds the long run growth rate. It also implies that, during the cycle, the instantaneous interest rate always exceeds the instantaneous growth rate. This implies that at the beginning of a cycle, implementation is never delayed, because any gain in profits from delay is less the rate at which it is discounted. However, during the downturn, this the left side of (51) also implies that implementation is delayed until the next boom, (E2). To understand this, note that the boom is the only time during the cycle at which the increment in output exceeds the increment in the discount factor. Although, the increment in productivity, $\Gamma$, exactly equals the increment in the discount factor, $\beta$, the reallocation of resources back into production implies that output increases by more than the increment in productivity. Thus, the increase in profits at the boom exceeds the rate at which they are discounted. If the probability of being displaced is sufficiently low (which it is towards the end of the cycle), there is an incentive to delay implementation. The right-hand inequality in (51) is necessary for (E4) to be satisfied, so that not all sectors innovate during the cycle. It is also sufficient to ensure that the value of immediate implementation, $V^{I}(t)$, declines monotonically during the slowdown. Since, at the beginning of the cycle, $\delta V^{I}\left(T_{v-1}\right)=w_{v}$, (E3) follows.

The parameter restrictions imposed by (51) are stronger than those needed for the existence of the acyclical equilibrium in (19). Note, however, that while they are sufficient for existence they are not necessary. In particular, the cyclical equilibria can exist even if the condition that $\gamma(1-\sigma)-\sigma<\frac{\rho}{\delta}$, is violated. Table 1 (in Section 5) gives some parameter examples that satisfy (51), and yield long run growth rates in the 2-3\% range. Perhaps the strongest implication of these restrictions is that $\sigma$ must be strictly below 1 . This should not be surprising: the existence of the cycle depends in part on the willingness of households to put off consumption during the downturn in exchange for a high return on their savings during the boom. ${ }^{18}$

\footnotetext{
${ }^{18}$ Estimates of $\sigma$ based on aggregate consumption data typically exceed 1 . However, as Beaudry and van Wincoop (1996) document, these estimates are biased upwards. When one uses more disaggregate data, values below 1 cannot be rejected.
} 


\subsection{Stability}

\subsubsection{Stability of the instantaneous equilibrium}

In every instant of the cycle, labor chooses between entrepreneurship and production, entrepreneurs choose between implementing today or delaying until tomorrow, and incumbents must decide whether to sell now or store. We now consider the stability of the instantaneous equilibrium with respect to each of these decisions in turn:

Stability in the labor market: Consider a small perturbation of the equilibrium such that at $t$, too little labor, by an amount $\varepsilon$, flows into entrepreneurship. In the slowdown, production strictly dominates entrepreneurial effort, $w(t)>\delta \max \left[V^{D}(t), V^{I}(t)\right]$. Small errors of this kind, will thus not affect others' optimal behavior. The same is not true, however, in the downturn, when $w(t)=\delta V^{D}(t)$. Then from (33) the short-run growth rate is given by $g(t)=-\frac{\rho}{\sigma}+\varepsilon$. It

follows from $(15)$ that $r(t)>0$, so that $\frac{\dot{V}^{D}(t)}{V^{D}(t)}>0$, which, since $\frac{\dot{w}(t)}{w(t)}=0$, implies more labor will be allocated to entrepreneurship. Thus, since a smaller than equilibrium flow into entrepreneurship induces greater incentives for entrepreneurship, the relationship is stable.

Stability of entrepreneurial delay: Suppose now that some measure of entrepreneurs erroneously implement their innovations immediately during the downturn rather than delaying. Such unanticipated implementation leaves $V^{D}(t)$ unchanged because the technology in use at the time of the boom is unchanged - some of it has just been implemented earlier. However, it raises $V^{I}(t)$ due to the unexpected increase in productivity of technology $\tau \in\left[t, T_{v}\right]$. Since $V^{D}(\tau)$ is discretely bigger than $V^{I}(\tau)$ over this phase, a small deviation from the equilibrium has no effect on incentives to delay. This is true even the instant before implementation, since $\lim _{\tau \rightarrow T_{v}} V^{D}(\tau)-V^{I}(\tau)=0$. This limit still converges following a surprise implementation, since the two terms must be equivalent at $T_{v}$. Thus, although earlier implementation raises $V^{I}$ relative to $V^{D}$, it cannot alter the relative ranking of the two.

Stability of No-Storage: Long-run asset market clearing in a cyclical equilibrium requires that the return on claims to firm profits equals the return to storage in the last instant of the cycle, $\beta\left(T_{v}\right)=\Gamma$. Consider a mistaken offer to finance the production of extra intermediate output for storage, by buying claims to the stored output. This act effectively draws labor effort out of entrepreneurship causing the anticipated value of $\Gamma$ to decline so that $\beta\left(T_{v}\right)>\Gamma$. In the next instant the buyer will be better off selling the intermediate output and using the proceeds to finance entrepreneurs, which will restore the equilibrium. 


\subsubsection{Dynamic stability}

A second notion of stability relates to the dynamic convergence of the economy to its long-run growth path. Like the acyclical growth path, the cyclical equilibrium is "jump stable". As our

analysis demonstrates, there is a unique triple $\left(\Gamma, \Delta^{E}, \Delta\right)$ that is consistent with equilibrium. Thus the economy necessarily involve jumps to this long run path since no other $\left(\Gamma, \Delta^{E}, \Delta\right)$ triple can hold, even in the short run, without violating the equilibrium conditions. In principle, the economy could jump to the acyclical equilibrium if expectations regarding which equilibrium the economy is in were to change in a coordinated way. However, it should be emphasized that the cycles generated by our model are not the result of exogenous shifts in expectations, as in Evans, Honkapohja and Romer (1998) for example. Note finally that there is one element of indeterminacy in the cycling equilibrium; the length of the first cycle $\Delta_{0}$ is indeterminate on the interval $\left[\Delta^{E}, \Delta\right]$ since there is no previous entrepreneurship phase to pin it down.

\section{Implications for Growth, Welfare and Volatility}

In this section we compare the long-run growth rates in the cycling and acyclical economies and examine the impact of changes in the productivity of innovative effort.

\subsection{Growth and Welfare in Cyclical and Acyclical Economies}

Let the average growth rate in the cycling equilibrium be denoted

$$
g^{c}=\Gamma / \Delta
$$

and recall the acyclical equilibrium growth, $g^{a}$ given in (20). Then we have

Proposition 6 The long run growth rate in the cyclical equilibrium $g^{c}$ exceeds that in the acyclical equilibrium, $g^{a}$.

The cyclical equilibrium yields higher average growth because all entrepreneurship occurs in the downturn when growth is negative and the interest rate is low relative to the economy's long run average. Thus compared with the acyclical economy where the interest rate is constant, the same expected flow of profits for the same expected length of incumbency has higher value in the cycling economy, thereby inducing more entrepreneurship and higher growth. 
Although the long-run growth rate is higher in the cyclical equilibrium, the same is not true of welfare. Consider two economies that start with an identical stock of implemented technologies and zero unimplemented innovations. Suppose one of the economies is in a cyclical equilibrium at the beginning of a cycle and the other is in an acyclical equilibrium. Then:

Proposition 7 Welfare in the acyclical economy exceeds that in the cyclical one.

There are three key differences that determine relative welfare in the two economies: (1) the long-run growth rate in the cyclical economy is higher, (2) the initial consumption in the cyclical economy is higher because some labor is allocated to production in the acyclical economy, whereas none is during this phase of the cyclical equilibrium, and (3) until the next boom, the short-run growth rate in the cyclical economy is zero or negative, whereas it is positive in the acyclical one. As the Proposition demonstrates, this last factor dominates, so that welfare is lower in the cyclical economy.

\subsection{Impact of Entrepreneurial Productivity}

Consider the impact of an increase in entrepreneurial productivity $\delta$ on the cyclical growth path. ${ }^{19}$

Lemma 4 An increase in $\delta$ results in shorter cycles, smaller booms and shorter recessions.

To understand these results first consider Figure 2. For a given cycle length and downturn length $\left(\Delta, \Delta^{E}\right)$, an increase in $\delta$ causes the size of the boom to be larger because entrepreneurship is now more productive. This is illustrated by the outward shift in OA to OA'. However, now the economy would be to the right of $\mathrm{OB}$, so that the asset market is out of equilibrium, with $\beta<\Gamma$ just prior to the boom, so that there is an incentive to store. Arbitrageurs would be willing to offer incumbents and entrepreneurs incentives to produce more intermediate output than needed to supply current demand. In particular, entrepreneurs with unimplemented innovations would respond by bringing production forward slightly from the boom. But if all entrepreneurs do this, the boom would actually occur earlier and the incentive to store would disappear. Applying this argument recursively, one can see that the length of the downturn (and hence the entire) cycle would fall until it is just short enough to ensure that for the (smaller) size of the boom that results, the incentive to produce early and store has been removed (i.e. $\beta=\Gamma$ just prior to the

\footnotetext{
${ }^{19}$ In our model human capital is normalized to unity. However, in a more general set up, varying the amount of human capital would be equivalent to varying $\delta$.
} 
boom). Thus, as noted in the Lemma, the cycle length, recession length and boom size, would all fall.

The economy's volatility is also affected by a change in $\delta$. Since the standard deviation is not well-defined in our context, we measure volatility as the average absolute size of deviations in log output from trend:

$$
\Sigma=\frac{1}{\Delta} \int_{0}^{\Delta-\Delta^{E}}\left|\Gamma-g^{c} t\right| d t+\frac{1}{\Delta} \int_{\Delta-\Delta^{E}}^{\Delta}\left|\Gamma-\frac{\rho}{\sigma}\left(t-\left(\Delta-\Delta^{E}\right)\right)-g^{c} t\right| d t
$$

The variable $\delta$ affects this through numerous channels; $\Delta, \Delta^{E}$ and $g^{c}$. Though the affects on phase lengths are unambiguous (see Lemma 4), the relationship between on $g^{c}$ and $\Sigma$ is not analytically clear. The first three rows of Table 1 shows how growth, volatility and cycle length vary with changes in $\delta$, within the parameter space given by (51). These numerical examples illustrate what extensive simulations show is a more general result:

The long-run relationship between growth, $g^{c}$, and volatility, $\Sigma$, across economies with different levels of entrepreneurial productivity is negative.

Thus, the relationship between growth and volatility across cyclical equilibrium is, at least superficially, consistent with the empirical results of Ramey and Ramey (1995). Note however that this relationship does not represent the impact of volatility on growth, nor the impact of growth on volatility. Rather it is an induced relationship due to variation in the productivity of entrepreneurship. Note further that, as Table 1 illustrates, the relationship induced by changes in other parameters is not always negative.

Table 1: Growth and Volatility

\begin{tabular}{llllrrr}
\hline \multicolumn{2}{l}{ Benchmark Parameters } & \multicolumn{2}{l}{ Long Run } & \multicolumn{2}{l}{ Volatility } & \multicolumn{2}{l}{ Cycle } \\
$\delta$ & $\gamma$ & $\rho$ & $\sigma$ & Growth, $(\%)$ & $\Sigma$ & \\
Length, $\Delta$ \\
\hline 2.0 & 0.120 & 0.025 & 0.25 & 2.67 & 0.194 & 3.8 \\
2.4 & & & & 3.26 & 0.186 & 2.6 \\
1.8 & & & & 2.38 & 0.200 & 4.9 \\
& 0.115 & & & 2.44 & 0.190 & 4.4 \\
& 0.125 & & & 2.91 & 0.201 & 3.4 \\
& & 0.022 & & 2.70 & 0.189 & 3.3 \\
& 0.028 & & 2.64 & 0.199 & 4.4 \\
& & 0.20 & 2.68 & 0.202 & 2.7 \\
& & 0.27 & 2.66 & 0.191 & 4.4
\end{tabular}




\section{Implications for the Business Cycle}

We have detailed a mechanism through which the process of creative destruction that drives growth in a multi-sector economy can also result in endogenous fluctuations due to strategic complementarity. While we do not claim that the model can provide a full account of the business cycle, in this section we consider the extent to which some essential features of the implied cyclical process are qualitatively consistent with the facts. In our conclusion we also discuss several extensions to the model that we believe will allow it to match the data more closely. We emphasize that our discussion relates more closely to the NBER definition of the business cycle, rather than the quarter-to-quarter fluctuations emphasized by the RBC literature.

\subsection{The Downturn is not a Consequence of Mismeasurement}

The downturn in our cycle results from the allocation of labor to entrepreneurship in anticipation of the upcoming boom. Since this reallocation represents an investment in intangible assets, one may wonder whether the implied downturn is really just a result of mismeasurement which would disappear if we included intangible investment, $I(t)$, in computing aggregate GDP. If we did so, aggregate GDP during the downturn would be

$$
\begin{aligned}
G D P & =c(t)+I(t)=y(t)+w_{v} X(t) \\
& =\pi(t)+w_{v}[1-X(t)]+w_{v} X(t) \\
& =\left(1-e^{-\gamma}\right) y(t)+w_{v} .
\end{aligned}
$$

Thus, the downturn does not arise from mismeasurement - even though the wage is constant through the cycle, GDP declines because profits decline. ${ }^{20}$ This is because imperfect competition in the intermediate sector implies that the total marginal cost of labor leaving production (i.e. its marginal product) exceeds the private marginal cost (i.e. the wage). Although workers are equally well off in the two activities, the re-allocation has a negative externality on current profits. $^{21}$

\subsection{Stockmarket Implications}

Our model also has predictions for the cyclical behavior of the stockmarket. In particular, it predicts that although the average value of firms on the stock market is not strictly procyclical,

\footnotetext{
${ }^{20}$ Computing GDP at factor cost (profits plus wages) yields the same result.

${ }^{21}$ A similar implication emerges in the GPT driven downturn discussed by Helpman and Trajtenberg (1998).
} 
it does anticipate movements in GDP. To see this, observe that the stock market in our model consists of three types of firm: incumbents in sectors where no new innovations have occurred, "terminal" incumbents in sectors where innovations have occurred, and new entrants in those sectors that have not yet implemented, but have value. ${ }^{22}$ In the slowdown, only the first type of firm exists, but during the downturn all three are present. At any point in time the measure of sectors in which no innovation has occurred is $P(t)$, therefore the total value of firms on the stockmarket is given by

$$
\Pi(t)=(1-P(t))\left[V^{T}(t)+V^{D}(t)\right]+P(t) V^{I}(t),
$$

where $V^{T}(t)$ denotes the value of "terminal" firms who are certain to be made obsolete during the next wave of implementation. The value of these firms can be written as

$$
V^{T}(t)=V^{I}(t)-\frac{P\left(T_{v}\right)}{P(t)} V^{D}(t)
$$

Substituting into (55) yields

$$
\Pi(t)=V^{I}(t)+(1-P(t))\left[1-\frac{P\left(T_{v}\right)}{P(t)} V^{D}(t)\right] .
$$

During the slowdown, $P(t)=1$ so that $\Pi(t)=V^{I}(t)$. Immediately prior to the boom $P(t)=$ $P\left(T_{v}\right)$, so that again $\Pi\left(T_{v}\right)=V^{I}\left(T_{v}\right)$. Thus, the evolution of the aggregate value of the stockmarket during the cycle resembles that of incumbent firms in sectors that have not yet innovated, $V^{I}(t)$, (see Figure 3) except that during the downturn it is always higher, reflecting the fact that incumbents with uncertain longevity are being replaced by new entrants who will have incumbency for at least one full cycle length. ${ }^{23}$

Thus, although the value of the stockmarket increases during the boom (although less so than output), it falls during the slowdown, in anticipation of the subsequent recession, and rises during the downturn, in anticipation of the subsequent boom. This cyclical anticipation of future profits implicit in aggregate stock prices accords well with the findings of Hall (2001), who compares the growth rate of cash flows implicit in securities values with the actual five-year forward growth rate of cash flow (see his Figure 9). He argues that between 1955 and 2000, aggregate movements in the stockmarket over the business cycle were validated by subsequent profit experience. While, of course, much of the variation in profits reflect unexpected shocks to the economy, Hall's results are

\footnotetext{
${ }^{22}$ More generally, we could interpret firms as bundles of "ideas" which are implicitly valued in the traded shares.

${ }^{23}$ If it were not for this potential obsolescence, incumbents and entrants would be equally valued, since profits depend only on aggregate demand.
} 
consistent with the view that a significant component of cyclical fluctuations is indeed anticipated by equity markets.

\subsection{The Clustering of Implementation}

A crucial feature of the cycle is that the implementation of innovations is clustered over time and is pro-cyclical. Indeed, this is a feature our model shares with the pure RBC model, although our interpretation of a business cycle is somewhat different and we actually model the clustering rather than assume it arises exogenously. Recently, a number of authors including Burnside, et al.(1995) and Basu (1996) have questioned the importance of shocks to technology. In particular, once one takes account of variations in capital utilization and labor hoarding over the cycle, the implied movements in TFP are much smaller and much less procyclical. However, King and Rebelo (2000) argue that once one endogenizes variations in factor utilization (by introducing adjustment costs), large fluctuations in output can result from small changes in TFP. Moreover, the TFP movements needed to account for output movements, are hardly ever negative, and hence more consistent with their interpretation as technology improvements.

There is, however, more direct evidence of procyclical clustering of implementation during booms. Geroski and Walters (1995) investigate high frequency movements in both the granting of patents in the US to UK firms and the implementation of major innovations in the UK for the period 1948-83. They find that the implementation of innovations and patenting activity are procyclical, ${ }^{24}$ and that they occur in small (several year) clusters. Based on Granger causality tests, they argue that changes in demand cause changes in innovation. However, Collins and Tao (1998) demonstrate that the econometric methodology underlying this last result is invalid and argue that the relationship likely exhibits two-way causation. More generally, Griliches' (1990) survey on patents also concludes that the basic procyclicality of patenting, first suggested by Schmookler (1966), has not been overturned.

\subsection{The Countercyclicality of Innovative Effort}

Another central feature of the equilibrium cycle is that innovative effort is countercyclical. One often used measure of innovative effort is R\&D expenditure. Fatas (2000) documents that growth in real R\&D expenditures in the US is positively correlated with real GDP growth. However, if we

\footnotetext{
${ }^{24}$ Though Geroski and Walters term their observations "innovations", their data involves the actual implementation of innovations. It therefore corresponds to implementation in our terminology.
} 
consider only privately funded $\mathrm{R} \& \mathrm{D}$ and distinguish between basic research, which is not generally driven by commercial considerations (and is a small proportion of the total), and applied research which is, then this stylized fact is not so clear. There is, in fact, no significant correlation between growth rates in real applied research (NSF data) and real GDP for the US over the period 1953 to 1999. As may be seen in Figure 5, although the big increases during the 50s and 60s appear to occur during booms, those of 1973-74, 1981 and 1991 occur during recessionary periods. The increase during the mid-1990s is an outlier in this regard, perhaps associated with the IT boom, but it is interesting to note that during the period of rapid GDP growth in 1998, applied research declines.

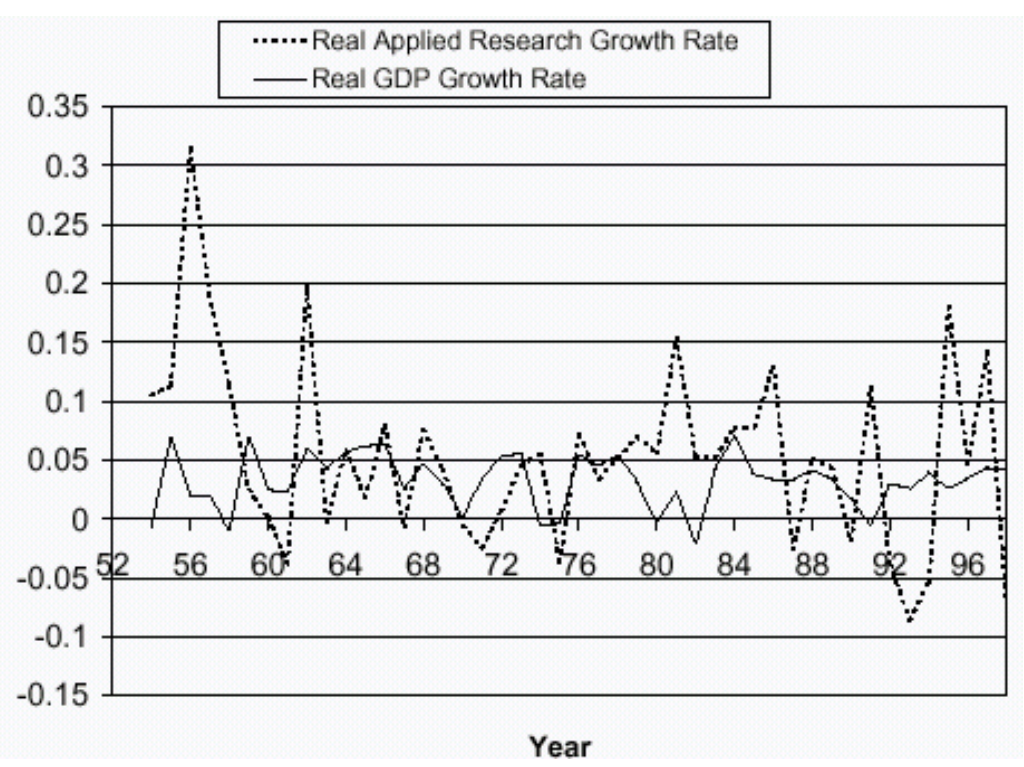

Figure 4: Applied Research and GDP Growth in the US

On the whole then, the evidence on R\&D expenditures is not strongly supportive of either a pro- or counter-cyclical view. However, innovation is a much broader concept than that measured by $R \& D$ investment. Much of the entrepreneurial function in modern production is undertaken by skilled workers and managers within industries. ${ }^{25}$ Since much of their innovative effort occurs without separately measured expenditures or occupational reallocation, the usual aggregate data sets are not helpful. Instead, what we require is detailed information about plant level activities. Although the evidence so far is disparate, a number of studies (discussed below) have used either

\footnotetext{
${ }^{25}$ This interpretation of innovation is not unlike the "reorganization" activity emphasized by Hall (2000). Note that although incumbents in our model would not engage in innovation within their own product line, they do have an incentive to innovate in other product lines.
} 
specialized data sets based on surveys or proxies to obtain related estimates. ${ }^{26}$

A frequently emphasized feature of business cycles is the apparent employment of labor during recessions beyond that which is technologically necessary to meet regular production requirements. Recently, the RBC literature has argued that this behavior reflects "labor hoarding" like capital, there are significant costs to adjusting labor (e.g. hiring and firing costs) which cause firms to hold on to skilled labor during recessions. However, another interpretation is that this labor is actually doing something productive - coming up with new ideas and approaches that will be useful in the future. In a survey of US manufacturing plants, Fay and Medoff (1985) find that during a trough quarter the typical plant paid for about 8 percent more labor hours than technologically necessary. Only half of this was hoarded labor - the remainder was used in other productive activities. Of the respondents that re-assigned workers during recessions (more than half of respondents), about one third allocated them to "reworking output" and another third to "training".

One might suspect that innovative activities are more likely to require skilled, non-production workers, so that during downturns the ratio of skilled to unskilled workers should rise. Although this is typically the case in the data, it is possible that this is motivated by labor hoarding since the costs of adjustment for skilled workers are relatively high. However, such a motivation would not lead to an absolute increase in skilled employment during a downturn. Using Spanish Manufacturing data (a balanced panel of 1080 non-energy manufacturers from 1986-1991), Aguirregabiria and Alonso-Borrego (2001) find the employment of white collar workers to be significantly countercyclical - a $1 \%$ decrease in real sales implied a $19 \%$ decrease in employment of blue collar workers, but a short term increase of $14 \%$ and $16 \%$ in employment of professionals and managers, respectively.

More direct evidence of what managers are doing during downturns is provided by Nickell, Nicolitsas and Patterson (2001). They investigate whether managerial innovations occur in downturns using 2 unique data sets. The first, based on the Confederation of British Industries Pay Databank (66 manufacturing firms during the period 1981-86) includes information on two measures of innovation - the removal of restrictive practices and the introduction of new technology. The second data set includes small to medium sized manufacturing firms in engineering, plastics,

\footnotetext{
${ }^{26}$ If we interpret innovative effort even more broadly to include any withdrawal of labor effort from contemporaneous production to activities that increase future productivity, it is also suggestive that post-secondary educational investments in OECD countries are counter-cyclical (Sakellaris and Spilimbergo, 2000).
} 
electronics and food, drink and tobacco. This categorizes levels of managerial innovation from 91-94 and compares them to lagged performance variables from the period $88-91 .^{27}$ Both data sets support the view that when demand is slack and profitability low, managers and workers devote more time to innovation. In the second data set, for example, a fall in profit per employee of 2000 British pounds or more led to a 40 to 60 percentage point increase in the probability that the level of managerial innovation increases from moderate to major in the subsequent period.

\subsection{Downturns and Subsequent Productivity Growth}

In the cyclical process implied by our model, larger downturns are associated with bigger booms. This is broadly consistent with the aggregate empirical characterizations of Pesaran and Potter (1997) and Altissimo and Violante (2001). More direct evidence is provide by Atella and Quintieri (1998). Using Italian data for 9 industries from 1967 to 1990, they find strong evidence that downturns tend to be followed by subsequent increases in TFP. The correlation of negative demand movements with subsequent TFP growth was greater than either public capital or R\&D expenditures. In a similar study for 2-digit SIC industries in the US (using the NBER annual productivity database from 1958-1991), Malley and Muscatelli (1999) find that demand reductions to manufacturing as a whole are significantly positively correlated with subsequent TFP growth. ${ }^{28}$

The notion that downturns will enhance long-run growth, is often associated with the impact of negative shocks in the context of Schumpeterian growth models. The reason is that by lowering wages, recessions reduce the opportunity costs of innovative effort and induce greater productivity improvements (see Aghion and Saint Paul (1998) for a survey). However, as illustrated by Barlevy (2001), while this may be socially optimal, it is not a necessary consequence of a decentralized equilibrium in all Schumpeterian growth models. ${ }^{29}$ Moreover, it should be recognized that this "opportunity cost" view of recessions emphasizes a different mechanism from that driving the relationship between recessions and booms here. In the cyclical equilibrium that we detail, wages

\footnotetext{
${ }^{27}$ The managerial innovation variables included: significant change in structure; organization leaner as result of change; significant changes resulting in more decentralized organization; significant changes in human resources management practices and industrial relations; the implementation of just in time technologies.

${ }^{28}$ At a more disaggregated level, they find that temporary industry level downswings are associated with long term productivity gains (9 out of 20 industries showed a significant relationship between demand innovations and subsequent TFP growth, with all but one being negative. These effects tended to be highest in those sectors with high job reallocation rates, controlling for capital intensity.

${ }^{29}$ Barlevy (2001) shows that, in the presence of aggregate shocks, the timing of innovations may be an additional source of inefficiency in the Schumpeterian growth process.
} 
are constant during the downturn (there is no negative "shock"). The clustering of innovation occurs because the discounted benefits rise as the next boom approaches - the downturn is a consequence of the withdrawal of labor from production, not a cause.

\section{Concluding Remarks}

This paper has established the existence of cycles along a balanced growth path of a completely standard multi-sectoral Schumpeterian growth model that allows for the possibility of delayed implementation and storage. Specifically, we show that: even with multiple sectors, in general equilibrium, with reasonable assumptions on preferences, technology and market competition, no static increasing returns to scale, no stochastic expectations, no threshold effects, and rational forward looking behavior, there exists a business cycle that is interlinked with the economy's growth process. Moreover, we establish conditions under which a unique cycling equilibrium arises.

The endogenous cycles generated by our model have several features that we believe are crucial to understanding actual business cycles. First and foremost, the cyclical fluctuations are the result of independent actions by decentralized decision-makers. They are not the result of economy-wide shocks or economy-wide technological breakthroughs, but emerge as a result of pecuniary demand externalities that induce coordination. This is true of both the boom, which reflects Shleifer's formalization of "animal spirits" in the joint implementation of innovations, and of the downturn, which reflects the common incentives of entrepreneurs in anticipation of the upcoming boom. Second, as in our cycle, the quantitative analyses of Emery and Koenig (1992), Sichel (1993) and Balke and Wynne (1995), suggest that the average cycle starts with a growth spurt which is then followed by a growth slowdown before the economy enters a period of relatively constant decline during the recessionary phase. Thirdly, as is consistent with the findings of Pesaran and Potter (1997) and Altissimo and Violante (2001) there is a positive feedback from downturns to subsequent cyclical upturns. Finally, the equilibrium relationship between growth and volatility is negative, which is consistent with the cross-country evidence of Ramey and Ramey (1995).

A valuable feature of the model developed here is its parsimony. Apart from a slight generalization of preferences, the model is identical to Grossman and Helpman (1991, Ch. 4). The ultimate value of theoretical endeavors aimed at understanding the interactions between growth 
and cycles will be in their ability to provide a convincing account of the high frequency data. While the model fits some features of the "normal" business cycle, we do not claim to have done that yet. However, the model's simplicity allows it to be used as a platform for these more empirically motivated extensions. The central mechanism described here is robust to extensions which shall be explored in future work, and which we briefly describe below:

- Abruptness of the boom - The growth spurt and the start of the slowdown are unrealistically abrupt. In reality expansions tend to be spread out over time, so that positive growth is more common than zero or negative growth. However, the expansion can be made longer and smoother by allowing for a period of learning-by-doing in sectors with newly implemented innovations, such that maximum productivity is not achieved immediately. ${ }^{30}$ In contrast to Shleifer (1986), innovations are not immediately imitated upon implementation and incumbents retain their position for the duration of the cycle. So long as firms learn quickly enough to ensure that the initial wage exceeds the value of entrepreneurship, the cycle continues to exist.

- Tangible capital assets - Although we allow for saving through intangible assets and for the possibility of storing output, we assume away physical capital as a vehicle for smoothing aggregate consumption over time. Introducing physical capital that is completely liquid would destroy the cyclical equilibrium because households would try to consume the anticipated benefits of the boom in advance by dis-saving. However, suppose (realistically) that capital exhibits "putty-clay" characteristics, and the capital-labor ratio cannot be adjusted fully except through expansion, then the cyclical equilibrium would still exist. During the downturn, capital would be left idle as complementary labor resources shift out of production. Because of the high opportunity cost (the return on intangible assets), investment in new capital would be delayed until after the initial boom that is associated with implementation and the increased utilization of existing capital.

- Aggregate uncertainty - The length and other characteristics of actual business cycles, vary from cycle to cycle and look rather different from the deterministic equilibrium cycle described here. However, introducing a degree of aggregate uncertainty would be possible without changing the basic analysis. For example, the stochastic arrival of GPTs that raises productivity in all sectors, say, would cause the size and length of booms and recessions between GPTs to vary over time. Moreover, the indeterminacy regarding the length of the initial cycle can yield a sunspot equilibrium in which the cycle is inevitable, but the length of the cycle is stochastic.

\footnotetext{
${ }^{30}$ Alternatively one could introduce adjustment costs in the reallocation of labor across sectors.
} 


\section{Appendix}

Proof of Proposition 1: From the household's Euler equation we have

$$
\sigma g(t)+\rho=r(t)
$$

Differentiating (18) yields $\frac{\dot{V}(t)}{V(t)}=\frac{\dot{w}(t)}{w(t)}=g(t)$. Substituting into (17) and rearranging gives

$$
r(t)=\frac{\delta\left(1-e^{-\gamma}\right)(1-X(t))}{e^{-\gamma}}+\delta \gamma X(t)-\delta X(t)
$$

Equating (58) and (59) and solving for the stationary allocation of labor to entrepreneurship thus yields

$$
X(t)=X^{*}=\frac{\delta\left(1-e^{-\gamma}\right)-\rho e^{-\gamma}}{\delta-(1-\sigma) e^{-\gamma} \delta \gamma} .
$$

Substituting into (16) gives (20). Note that with $\sigma<1$, the existence of a positive growth path requires that $\delta\left(1-e^{-\gamma}\right)>\rho e^{-\gamma}$ which rearranges to the second inequality in (19). Also for utility to bounded and the transversality condition to hold requires that $r(t)>g(t)$. Using $(20)$ and (58) a sufficient condition given by the first inequality in (19).

Proof of Lemma 1 We show: (1) that if a signal of success from a potential entrepreneur is credible, other entrepreneurs stop innovation in that sector; (2) given (1) entrepreneurs have no incentive to falsely claim success.

Part (1): If entrepreneur $i^{\prime}$ s signal of success is credible then all other entrepreneurs believe that $i$ has a productivity advantage which is $e^{\gamma}$ times better than the existing incumbent. If continuing to innovate in that sector, another entrepreneur will, with positive probability, also develop a productive advantage of $e^{\gamma}$. Such an innovation yields expected profit of 0 , since, in developing their improvement, they do not observe the non-implemented improvements of others, so that both firms Bertrand compete with the same technology. Returns to attempting innovation in another sector where there has been no signal of success, or from simply working in production, $w(t)>0$, are thus strictly higher, .

Part (2): If success signals are credible, entrepreneurs know that upon success, further innovation in their sector will cease from Part (1) by their sending of a costless signal. They are thus indifferent between falsely signalling success when it has not arrived, and sending no signal. Thus, there exists a signalling equilibrium in which only successful entrepreneurs send a signal of success. 
Proof of Lemma 2: From the production function we have $\ln y(t)=\int_{0}^{1} \ln \frac{y(t)}{p_{i}(t)} d i$. Substituting for $p_{i}(t)$ using $(8)$ yields $0=\int_{0}^{1} \ln \frac{w(t) e^{\gamma}}{A_{i}\left(T_{v-1}\right)} d i 0$ which re-arranges to $(27)$.

Proof of Lemma 3: Note that in any preceding no-entrepreneurship phase, $r(t)=\rho$. Thus, since, in a cycling equilibrium, the date of the next implementation is fixed at $T_{v}$, the expected value of entrepreneurship, $\delta V^{D}$, also grows at the rate $\rho>0$. Thus, if under $X\left(T_{v}^{E}\right)=0$, $\delta V^{D}\left(T_{v}^{E}\right)>w_{v}$, then the same inequality is also true the instant before, i.e. at $t \rightarrow T_{v}^{E}$, since $w_{v}$ is constant within the cycle. But this violates the assertion that entrepreneurship commences at $T_{v}^{E}$. Thus necessarily, $\delta V^{D}\left(T_{v}^{E}\right)=w_{v}$ at $X\left(T_{v}^{E}\right)=0$.

Proof of Proposition 2: From (28), long-run productivity growth is given by

$$
\Gamma_{v+1}=\left(1-P\left(T_{v}\right)\right) \gamma
$$

Integrating (37) over the entrepreneurship phase and substituting for $X(\cdot)$ using (34) yields

$$
1-P\left(T_{v}\right)=\delta \int_{T_{v+1}^{E}}^{T_{v+1}}\left(1-e^{-\frac{\rho}{\sigma}\left[t-T_{v+1}^{E}\right]}\right) d \tau .
$$

Substitution into (61) and integrating gives (39).

Proof of Proposition 3: The increase in output from the beginning of one cycle to the beginning of the next reflects only the improvement in productivity $y_{0}\left(T_{v}\right)=e^{\Gamma_{v}} y_{0}\left(T_{v-1}\right)$. Moreover, since all output is consumed it follows that $c_{0}\left(T_{v}\right)=e^{\Gamma_{v}} c_{0}\left(T_{v-1}\right)$. This implies that the long run discount factor is given by $\beta(t)=\sigma \Gamma_{v}+\rho\left(T_{v+1}-T_{v}\right)-\int_{T_{v}}^{t} r(s) d s$. In particular, since $r(t)=0$ during the downturn, $\beta(t)=\sigma \Gamma_{v}+\rho \Delta_{v}^{E} \quad \forall t \in\left(T_{v}^{E}, T_{v}\right)$. Combining this with (43) and (44) yields (45).

Proof of Proposition 4: The discounted monopoly profits from owning an innovation at time $T_{v}$ is given by $V_{0}^{I}\left(T_{v}\right)=\left(1-e^{-\gamma}\right) \int_{T_{v}}^{T_{v+1}} e^{-\int_{T_{v}}^{\tau} r(s) d s} y(\tau) d \tau+P\left(T_{v}\right) e^{-\beta\left(T_{v}\right)} V_{0}^{I}\left(T_{v+1}\right)$. Substituting for $V_{0}^{I}\left(T_{v+1}\right)$ using (48), and integrating yields

$$
V_{0}^{I}\left(T_{v}\right)=\left(\frac{\left(1-e^{-\gamma}\right) y_{0}\left(T_{v}\right)}{1-P\left(T_{v}\right) e^{\Gamma-\beta\left(T_{v}\right)}}\right)\left[\frac{1-e^{-\rho\left(T_{v+1}^{E}-T_{v}\right)}}{\rho}+e^{-\rho\left(T_{v+1}^{E}-T_{v}\right)}\left(\frac{1-e^{-\frac{\rho}{\sigma} \Delta^{E}}}{\rho / \sigma}\right)\right] .
$$

Asset market clearing during the boom and the fact that $X\left(T_{v}\right)=0$ implies (using (11)) that $\delta V_{0}^{I}\left(T_{v}\right)=w_{v+1}=e^{-\gamma} y_{0}\left(T_{v}\right)$. Substituting into (63) we have

$$
\left(1-e^{-\gamma}\right) \delta\left[\frac{1-e^{-\rho\left(T_{v+1}^{E}-T_{v}\right)}}{\rho}+e^{-\rho\left(T_{v+1}^{E}-T_{v}\right)}\left(\frac{1-e^{-\frac{\rho}{\sigma} \Delta^{E}}}{\rho / \sigma}\right)\right]=e^{-\gamma}\left(1-P\left(T_{v}\right) e^{\Gamma-\beta\left(T_{v}\right)}\right) .
$$


But $\beta\left(T_{v}\right)=\rho\left(T_{v+1}^{E}-T_{v}\right)+\Gamma$, so that multiplying through by $e^{\rho\left(T_{v+1}^{E}-T_{v}\right)}$ and collecting terms yields

$$
\left(\frac{\left(1-e^{-\gamma}\right) \delta}{\rho}-e^{-\gamma}\right)\left(e^{\rho\left(T_{v+1}^{E}-T_{v}\right)}-1\right)=e^{-\gamma}\left(1-P\left(T_{v}\right)\right)-\left(1-e^{-\gamma}\right) \delta\left(\frac{1-e^{-\frac{\rho}{\sigma} \Delta^{E}}}{\rho / \sigma}\right) .
$$

Since $\left[1-P\left(T_{v}\right)\right] \gamma=\Gamma_{v}$ from (45) we have that $1-P\left(T_{v}\right)=\frac{\rho \Delta^{E}}{\gamma(1-\sigma)}$, substituting this into the above, using (46) to substitute out the second term on the right hand side, and rearranging yields

$$
e^{\rho\left(T_{v+1}^{E}-T_{v}\right)}=1+\mu \Delta^{E}
$$

where $\mu$ is defined in (50). Taking logs and noting that $T_{v+1}^{E}-T_{v}=T_{v+1}-T_{v}-\Delta^{E}=\Delta_{v}-\Delta^{E}$ yields (49).

Proof of Proposition 5: It is easily verified that under (51) there does exist a unique triple $\left(\Delta^{E}, \Delta, \Gamma\right)>0$ which solves (39), (45) and (49). The remainder of the proof shows that each of the conditions (E1) through (E4) under (51):

(E1): Since $V_{0}^{I}\left(T_{v+1}\right)=e^{\Gamma} V_{0}^{I}\left(T_{v}\right)$, we can write $V_{0}^{D}\left(T_{v}\right)=e^{-\beta\left(T_{v}\right)+\Gamma} V_{0}^{I}\left(T_{v}\right)$. From the proof of Proposition 3, $\beta\left(T_{v}\right)=\rho \Delta+\sigma \Gamma$, so that condition (E1) requires that $\rho \Delta>(1-\sigma) \Gamma$, which must be true for the consumer's optimization problem to be bounded. Using (45), this condition simply requires that $\Delta>\Delta^{E}$, which, from (49) and the definition of $\mu$ in (50) is true as long as $\frac{\rho}{\delta}>\gamma(1-\sigma)\left(1-e^{-\gamma}\right)$. This holds if the left-hand inequality in (51) is satisfied.

(E2): This inequality can be written as

$$
V^{I}(t)=\int_{t}^{T_{v}} e^{-\int_{t}^{\tau} r(s) d s} \pi(\tau) d \tau+\frac{P\left(T_{v}\right)}{P(t)} V^{D}(t)<V^{D}(t) \quad \forall t \in\left(T_{v}^{E}, T_{v}\right)
$$

During the downturn we know that $V^{D}(t)=w_{v-1} / \delta=e^{-\gamma} y_{0} / \delta$ and $r(t)=0$. Substituting these and rearranging yields

$$
e^{-\gamma}\left(1-\frac{P\left(T_{v}\right)}{P(t)}\right)-\left(1-e^{-\gamma}\right) \delta\left(\frac{1-e^{-\frac{\rho}{\sigma}\left(T_{v}-t\right)}}{\rho / \sigma}\right)>0
$$

where $P(t)=1-\int_{T_{v}^{E}}^{t} \delta\left(1-e^{-\frac{\rho}{\sigma}\left[\tau-T_{v}^{E}\right]}\right) d \tau=1-\delta\left[t-T_{v}^{E}\right]+\delta\left(\frac{1-e^{-\frac{\rho}{\sigma}\left[t-T_{v}^{E}\right]}}{\rho / \sigma}\right)$. When $t=T_{v}$, this becomes $P\left(T_{v}\right)=1-\delta \Delta^{E}+\delta\left(\frac{1-e^{-\frac{\rho}{\sigma} \Delta^{E}}}{\rho / \sigma}\right)$. It is easily verified that $\ln P(t)$ is decreasing and convex in $t$. It follows that

$$
-\frac{\ln P\left(T_{v}\right)-\ln P(t)}{T_{v}-t} \geq\left.\frac{d \ln P(t)}{d t}\right|_{t=T_{v}}
$$


Let

$$
q=-\left.\frac{\sigma}{\rho} \frac{d \ln P(t)}{d t}\right|_{t=T_{v}}=\frac{\delta\left(\frac{1-e^{-\frac{\rho}{\sigma} \Delta^{E}}}{\rho / \sigma}\right)}{1-\delta \Delta^{E}+\delta\left(\frac{1-e^{-\frac{\rho}{\sigma} \Delta^{E}}}{\rho / \sigma}\right)} .
$$

Now note that condition (51) implies that $q>1$. To see this, note that it follows from (70) that $q>1$, if and only if $\delta \Delta^{E}>1$. So we first demonstrate that $\delta \Delta^{E}>1$. In Figure 2 , at the positive intersection of (39) and (45), the former (linear function) must be steeper than the latter (concave function). Differentiating these two curves, this implies that $\Delta^{E}$ must satisfy

$$
1-e^{-\frac{\rho}{\sigma} \Delta^{E}}>\frac{\rho}{\delta \gamma(1-\sigma)}
$$

Substituting using (46) this implies

$$
\delta \Delta^{E}>\frac{\sigma}{\gamma(1-\sigma)-\rho / \delta} .
$$

So that a sufficient condition for $\delta \Delta^{E}>1$ is that $\frac{\rho}{\delta}>\gamma(1-\sigma)-\sigma$, which must be true under (51).

We now have that $q>1$, and it follows that

$$
\log P\left(T_{v}\right)-\log P(t) \leq-q \frac{\rho}{\sigma}\left(T_{v}-t\right)
$$

Rearranging gives $1-\frac{P\left(T_{v}\right)}{P(t)} \geq 1-e^{-q \frac{\rho}{\sigma}\left(T_{v}-t\right)}$. It follows that a sufficient condition for $(68)$ is that

$$
e^{-\gamma}\left(1-e^{-q \frac{\rho}{\sigma}\left(T_{v}-t\right)}\right)-\left(1-e^{-\gamma}\right) \delta\left(\frac{1-e^{-\frac{\rho}{\sigma}\left(T_{v}-t\right)}}{\rho / \sigma}\right) \geq 0
$$

We know that (68), and hence (74), holds with equality at $t=T_{v}$, thus a sufficient condition is that the left hand side of (74) declines monotonically with $t<T_{v}$. That is

$$
-e^{-\gamma} q \frac{\rho}{\sigma} e^{-q \frac{\rho}{\sigma}\left(T_{v}-t\right)}+\left(1-e^{-\gamma}\right) \delta e^{-\frac{\rho}{\sigma}\left(T_{v}-t\right)}<0 \forall t \in\left[T_{v}^{E}, T_{v}\right] .
$$

Since $q>1, e^{-q \frac{\rho}{\sigma}\left(T_{v}-t\right)} \leq e^{-\frac{\rho}{\sigma}\left(T_{v}-t\right)}$, and so a sufficient condition is $q>\frac{\sigma\left(1-e^{-\gamma}\right) \delta}{\rho e^{-\gamma}}$. From (70), this inequality holds if

$$
\delta\left(\frac{1-e^{-\frac{\rho}{\sigma} \Delta^{E}}}{\rho / \sigma}\right)>\frac{\sigma\left(e^{\gamma}-1\right) \delta}{\rho}\left[1-\delta \Delta^{E}+\delta\left(\frac{1-e^{-\frac{\rho}{\sigma} \Delta^{E}}}{\rho / \sigma}\right)\right]
$$

Since $\delta \Delta^{E}>1$, (E2) will hold if $\frac{\rho}{\delta}>\sigma\left(e^{\gamma}-1\right)$. If, instead, however, $\frac{\rho}{\delta}<\sigma\left(e^{\gamma}-1\right)$, (E2) can still hold, so long as (51) is satisfied. To see this note that from (46)

$$
\Delta^{E}=\frac{1-e^{-\frac{\rho}{\sigma} \Delta^{E}}}{\rho / \sigma\left(1-\frac{\rho}{\delta \gamma(1-\sigma)}\right)}
$$


Substituting into (76) and rearranging yields:

$$
\left(\frac{\rho}{\delta \gamma(1-\sigma)}\right)^{2} e^{-\gamma}\left(1-\frac{\sigma\left(e^{\gamma}-1\right) \delta}{\rho}\right)<\frac{\rho}{\delta \gamma(1-\sigma)}-\left(1-e^{-\gamma}\right)
$$

Since the left hand side is negative when $\frac{\rho}{\delta}<\sigma\left(e^{\gamma}-1\right)$, it is sufficient that $\frac{\rho}{\delta}>\left(1-e^{-\gamma}\right) \gamma(1-\sigma)$, which is true under the left-hand inequality in (51).

(E3): Long-run market clearing implies that $\delta V^{I}\left(T_{v-1}\right)=w_{v}$. It follows that a sufficient condition for (E3) is $\frac{d V^{I}(t)}{d t}<0, \forall t \in\left(0, T_{v}^{E}\right)$. Since during this phase $r(t)=\rho$ and $g=0$, the value of immediate implementation can be expressed as

$$
V^{I}(t)=\left(1-e^{-\gamma}\right)\left(\frac{1-e^{-\rho\left(T_{v}^{E}-t\right)}}{\rho}\right) y_{0}\left(T_{v-1}\right)+e^{-\rho\left(T_{v}^{E}-t\right)} V^{I}\left(T_{v}^{E}\right) .
$$

Differentiating w.r.t. to $t$ yields

$$
\frac{d V^{I}(t)}{d t}=-\left(1-e^{-\gamma}\right) e^{-\rho\left(T_{v}^{E}-t\right)} y_{0}\left(T_{v-1}\right)+\rho e^{-\rho\left(T_{v}^{E}-t\right)} V^{I}\left(T_{v}^{E}\right)
$$

If (51) holds then from (E2), we have that $V^{I}\left(T_{v}^{E}\right)<w_{v} / \delta=e^{-\gamma} y_{0}\left(T_{v-1}\right) / \delta$, and so

$$
\frac{d V^{I}(t)}{d t}<-\frac{e^{-\rho\left(T_{v}^{E}-t\right)} y_{0}}{\delta}\left[\left(1-e^{-\gamma}\right) \delta-\rho e^{-\gamma}\right]<0 .
$$

This requires that $\frac{\rho}{\delta}<e^{\gamma}-1$. Since $e^{\gamma}-1>\gamma>\gamma(1-\sigma)$, this follows from the right-hand inequality of (51).

(E4): This is equivalent to $\Gamma<\gamma$. Substituting for $\Delta^{E}$ in (46) using (45) and rearranging slightly yields

$$
\frac{1-e^{-\frac{1-\sigma}{\sigma} \Gamma}}{\left(\frac{1-\sigma}{\sigma}\right) \Gamma}=1-\frac{\rho}{\delta \gamma(1-\sigma)}
$$

The left hand side of this equation is monotonically decreasing in $\Gamma$ (to see this note that $1-e^{-x}$ is an increasing, concave function of $x$ and its slope, $e^{-x}$, is just equal to 1 at $x=0$, and then declines with $x$ ). It follows that $\Gamma<\gamma$ requires that

$$
\frac{1-e^{-\frac{1-\sigma}{\sigma} \gamma}}{\left(\frac{1-\sigma}{\sigma}\right) \gamma}<\frac{1-e^{-\frac{1-\sigma}{\sigma} \Gamma}}{\left(\frac{1-\sigma}{\sigma}\right) \Gamma}=1-\frac{\rho}{\delta \gamma(1-\sigma)}
$$

So a necessary and sufficient condition for (E4) is $\frac{\rho}{\delta}<\gamma(1-\sigma)-\sigma\left(1-e^{-\frac{1-\sigma}{\sigma} \gamma}\right)$, which holds under the right hand inequality in (51). 
Proof of Proposition 6: Growth in the acyclical economy is given by $g^{a}$ in (20). In the cyclical economy, from (45) the average long run growth rate can be expressed as $g^{c}=\frac{\Gamma}{\Delta}=\frac{\rho}{1-\sigma} \frac{\Delta^{E}}{\Delta}$. Using (49) and the fact that for any $x>0, \ln (1+x)<x$ we have $\Delta<\Delta^{E}+\frac{\mu}{\rho} \Delta^{E}$. It follows that

$$
g^{c}>\frac{\rho}{1-\sigma} \frac{\Delta^{E}}{\left(\Delta^{E}+\frac{\mu}{\rho} \Delta^{E}\right)}=\frac{\left[\delta\left(1-e^{-\gamma}\right)-\rho e^{-\gamma}\right] \gamma}{1-(1-\sigma) \gamma e^{-\gamma}}=g^{a} .
$$

Proof of Proposition 7: Suppose that the economies start at $T_{0}$ with identical distributions of implemented innovations and no unimplemented innovations. Hence the maximum level of output, $\bar{y}\left(T_{0}\right)$, that could be produced if all labor were being used in manufacturing is the same in both equilibria. In the acyclical equilibrium, household welfare is given by

$$
W^{A}\left(T_{0}\right)=\frac{c\left(T_{0}\right)^{1-\sigma}}{1-\sigma}\left(\frac{1}{\rho-(1-\sigma) g^{a}}\right)=\frac{\bar{y}\left(T_{0}\right)^{1-\sigma}}{1-\sigma}\left(\frac{\left(1-X^{*}\right)^{1-\sigma}}{\rho-(1-\sigma) g^{a}}\right)
$$

where $X^{*}$ is the fraction of labor effort in entrepreneurship given by (60). In the cyclical equilibrium, household welfare at the beginning of the first cycle is

$$
\begin{aligned}
W^{C}\left(T_{0}\right) & =\frac{c\left(T_{0}\right)^{1-\sigma}}{1-\sigma} \sum_{v=0}^{\infty} e^{-\rho\left(\Delta-\Delta^{E}\right) v}\left\{\frac{1-e^{-\rho\left(\Delta-\Delta^{E}\right)}}{\rho}+e^{-\rho\left(\Delta-\Delta^{E}\right)}\left(\frac{1-e^{-\frac{\rho}{\sigma} \Delta^{E}}}{\rho / \sigma}\right)\right\} \\
& =\frac{\bar{y}\left(T_{0}\right)^{1-\sigma}}{1-\sigma}\left\{\frac{1}{\rho}+\frac{1}{\mu}\left(1-\frac{\rho}{\delta \gamma(1-\sigma)}\right)\right\}
\end{aligned}
$$

Observe that rearranging (84) yields $\frac{1}{\mu}=\left(\frac{1-\sigma}{\rho}\right) \frac{g_{a}}{\rho-(1-\sigma) g_{a}}$. Substituting into (86) and noting that $\frac{1}{\rho} \equiv \frac{1}{\rho-(1-\sigma) g_{a}}\left(1-\frac{(1-\sigma) g_{a}}{\rho}\right)$ yields

$$
W^{C}\left(T_{0}\right)=\frac{\bar{y}\left(T_{0}\right)^{1-\sigma}}{1-\sigma}\left(1-\frac{g_{a}}{\delta \gamma}\right) \frac{1}{\rho-(1-\sigma) g_{a}} .
$$

But since $g_{a}=\delta \gamma X^{*}$, it follows that the ratio of welfare in the cyclical economy to that in the acyclical one is given by $\frac{W^{C}\left(T_{0}\right)}{W^{A}\left(T_{0}\right)}=\left(1-X^{*}\right)^{\sigma}<1$. 


\section{References}

Aghion, Philippe and Howitt, Peter, "A Model of Growth Through Creative Destruction," Econometrica, vol. 60, 1992, pp. 323-351.

Aghion, Philippe and Peter Howitt, "Endogenous Growth Theory" Cambridge MIT Press, 1998. Aghion, Philippe, and Giles Saint Paul, "Uncovering some causal relationships between productivity growth and the structure of economic fluctuations: A tentative survey", Labor, vol. 12, 1998, 279-303.

Aguirregabiria, Victor and Cesar Alonso-Borrego, "Occupational Structure, Technological Innovation, and Reorganization of Production" Labour Economics, vol. 8 (1), 2001, pp. 43-73.

Altissimo, Filippo and Giovanni L. Violante, "The non-linear dynamics of output and unemployment in the US" Journal of Applied Econometrics, forthcoming.

Andolfatto, David and Glenn M. MacDonald, "Technology Diffusion and Aggregate Dynamics" Review of Economic Dynamics, vol. 1 (2), 1998, pp. 338-70.

Atella, Vincenzo and Beniamino Quintieri, "Productivity Growth and the Effects of Recessions," Giornale degli Economisti e Annali di Economia, vol. 57 (3-4), 1998, pp. 359-86.

Balke, N. and M. Wynne, "Recession and recoveries in real business cycle models" Economic Inquiry, vol. 33, pp. 1995, 640-663.

Barlevy, Gadi, "The timing of innovation in a Schumpeterian mofel of growth," mimeo, Northwestern University, Evanston, Illinois, 2001.

Basu, Susanto, "Procyclical Productivity: Increasing Returns or Cyclical Utilization?" Quarterly Journal of Economics, vol. 111 (3), 1996, pp. 719-51.

Beaudry, P. and G. Koop, "Do recessions permanently affect output?" Journal of Monetary Economics, vol. 31, 1993, 149-163.

Beaudry, P. and E. van Wincoop, "The Intertemporal Elasticity of Substitution: An Exploration using a US Panel of State Data" Economica, 63, 1996, pp. 495.

Burnside, Craig, Martin Eichenbaum and Sergio Rebelo, "Capital Utilization and Returns to Scale" Centre for Economic Policy Research, Discussion Paper No. 1221, 1995.

Cheng, L.K. and E. Dinopoulos, "Schumpeterian Growth and Stochastic Economic Fluctuations" mimeo, University of Florida, 1992.

Cohen, Wesley M., Richard R. Nelson and John P. Walsh, "Protecting Their Intellectual Assets: Appropriability Conditions and Why U.S. Manufacturing Firms Patent (or Not)" National Bureau 
of Economic Research Working Paper No. 7552, 2000.

Collins, Alan and Shujie Tao, "On Innovative Activity over the Business cycle: A Note" Applied Economics Letters, vol. 5 (12), 1998, pp. 785-788.

Emery, K.M. and E.F. Koenig, "Forecasting turning points: is a two-state characterization of the business cycle appropriate?" Economics Letters, vol. 39, 1992, pp. 431-435.

Evans, George W., Seppo Honkapohja and Paul Romer, "Growth Cycles" American Economic Review, vol. 88 (3), 1998, pp. 495-515.

Fatas, Antonio, "Do Business Cycles Cast Long Shadows? Short-Run Persistence and Economic Growth" Journal of Economic Growth, vol. 5 (2), 2000, pp. 147-62.

Fay, Jon-A. and James-L. Medoff, "Labor and Output over the Business Cycle: Some Direct Evidence" American Economic Review, vol. 75 (4), 1995, pp. 638-55.

Francois, Patrick and Shouyong Shi, "Welfare Improving Cycles" Journal of Economic Theory, 86, 1999, pp. 226-257.

Freeman, Scott, Dong Pyo Hong and Dan Peled, "Endogenous Cycles and Growth with Indivisible Technological Developments" Review of Economic Dynamics, vol. 2, 1999, 403-432.

Geroski, P.A. and C.F. Walters, "Innovative Activity over the Business Cycle" Economic Journal, vol. 105 (431), 1995, pp. 916-28.

Griliches, Zvi, "Patent Statistics as Economic Indicators: A Survey" Journal of Economic Literature, vol. 28 (4), 1990, pp. 1661-1707.

Grossman, Gene and Elhanan Helpman, Innovation and Growth in the Global Economy, Cambridge, MA.: MIT press, 1991.

Hall, Robert E., "Reorganization" Carnegie Rochester Conference Series on Public Policy; 52(0), 2000, 1-22.

Hall, Robert E., "Struggling to Understand the Stock Market" American Economic Review, vol. 91 (2), 2001, pp. 1-11.

Helpman, E. and M. Trajtenberg, "A Time to Sow and a Time to Reap: Growth Based on General Purpose Technologies" in Elhanan Helpman (ed.), General Purpose Technologies and Economic Growth, Cambridge: MIT Press, 1998.

Jovanovic, Boyan and Lach, Saul, "Product Innovation and the Business Cycle" International Economic Review; 38(1), 1998, pp. 3-22.

Jovanovic, Boyan and Rafael Rob, "Long Waves and Short Waves: Growth through Intensive 
and Extensive Search," Econometrica, vol. 58, 1990, pp. 1391-1409.

Keynes, John M., The General Theory of Employment, Interest and Money, Macmillan, 1936.

King, Robert G. and Sergio Rebelo, "Resuscitating Real Business Cycles" Rochester Center for Economic Reserach Working Paper No. 467, 2000.

Li, Chol Won, "Growth and Output Fluctuations" Scottish Journal of Political Economy, vol. 47 (2), 2000, pp. 95-113.

Malley, Jim and V. Anton Muscatelli, "Business Cycles and Productivity Growth: Are Temporary Downturns Productive or Wasteful?" Research in Economics, vol. 53(4), 1999, pp. 337-64.

Matsuyama, Kiminori, "Growing Through Cycles" Econometrica, 67 (2), 1999, pp. 335-47.

Nickell, Stephen, Daphne Nicolitsas, Malcolm Patterson, "Does Doing Badly Encourage Management Innovation?" Oxford Bulletin of Economics and Statistics, 63 (1), 2001, pp. 5-28.

Pesaran, M.H. and S. M. Potter "A floor and ceiling model of US output" Journal of Economic Dynamics and Control, 21, 1997, pp. 661-696.

Phillips, Kerk and Jeffrey Wrase, "Schumpeterian Growth and Endogenous Business Cycles" Federal Reserve Bank of Philadelphia Research Working Paper: 99/20, 1999.

Ramey, G. and V. A. Ramey, "Cross-Country Evidence on the Link Between Volatility and Growth," American Economic Review, vol. 85, 1995, pp. 1138-1151.

Sakellaris, P. and A. Spilimbergo, "Business Cycles and Investment in Human Capital: International Evidence on Higher Education" Carnegie Rochester Conference Series on Public Policy, $52,2000,221-56$.

Schmookler, Jacob, Invention and Economic Growth. Cambridge, Mass.: Harvard University press, 1966.

Schumpeter, J., "The Explanation of the Business Cycle" Economica, 1927, pp. 286-311.

Schumpeter, Joseph, Capitalism, Socialism and Democracy, 3rd edition, New York, 1950.

Segerstrom, Paul S., T. C. A. Anant and Elias Dinopoulos, "A Schumpeterian Model of the Product Life Cycle" American Economic Review, Vol. 80, No. 5., 1990, pp. 1077-1091

Shleifer, Andrei, "Implementation Cycles" Journal of Political Economy, vol. 94 (6), 1986, pp. 1163-1190.

Sichel, D.E., "Business Cycle Asymetry: A Deeper Look" Economic Inquiry, 31, 1989 224-36. Zarnowitz, Victor, "Has the Business Cycle been Abolished?" Business Economics, vol. 33 (4), 1998, pp. 39-45. 